\title{
A CPW fed two and four element antenna with reduced mutual coupling between the antenna elements for wireless applications
}

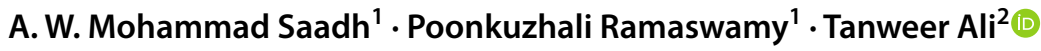

Received: 19 March 2020 / Accepted: 17 December 2020 / Published online: 9 January 2021

(c) The Author(s) 2021

\begin{abstract}
Mutual coupling between the multiple antenna designs is a critical problem which deteriorates the performance of multiple input multiple output (MIMO) system. It affects the antenna efficiency and influences the correlation. In this paper, a study on the isolation between the multiple antenna elements is presented. The antennas are placed on a cost-effective compact dielectric substrate with different orientations to minimize the correlation. A CPW fed antenna is designed using FR4 substrate, using which two and four element antenna structures are developed. The performance parameters are analysed, wherein the envelope correlation coefficient (ECC) has to be less than 0.5, diversity gain nearer to $10 \mathrm{~dB}$ in the operating bandwidth, mean effective gain (MEG) less than $3 \mathrm{~dB}$, channel capacity loss (CCL) less than $0.4 \mathrm{bits} / \mathrm{s} / \mathrm{Hz}$ and the isolation between the antenna elements well above $20 \mathrm{~dB}$. Acceptable gain, high radiation efficiency, and stable radiation pattern of the proposed design are analysed and the fabricated prototype of two and four element is measured for its performance parameters. All the necessary simulations are carried out in the EM simulator Ansys HFSS v.14.0 and a detailed comparison study is done based on the existing antennas.
\end{abstract}

Keywords Mutual coupling $\cdot$ ECC $\cdot$ Diversity gain $\cdot$ Channel capacity loss $\cdot$ Isolation

\section{Introduction}

The developing need for a rise in the data rates for wireless communication systems is increasing the demand for a productive and high data rate transmission system that can function in certain frequencies [1-3]. MIMO (multiple-input-multiple-output) system is one of the prominent solutions as it can enhance the channel capacity $[4,5]$. Its characteristics to transmit the data at a fast rate with low interference could potentially help the future wireless technology. This technology can immensely improve the channel capacity, data rate, and link safety of wireless systems by multi-path data communication [6]. These systems conduct the power through multiple antennas at the transmitter and

Tanweer Ali

tanweer.ali@manipal.edu

1 Division of Communication Engineering, School of Electronics Engineering, Vellore Institute of Technology, Vellore, India

2 Department of Electronics and Communication Engineering, Manipal Institute of Technology, Manipal Academy of Higher Education, Manipal, India receiver thereby enhancing the channel capacity without the use of supplementary bandwidth or power [7]. These systems are at present engaged in $4 \mathrm{G}$ user material and are a rising technology for service in the eventual 5G mobile terminals. Also, modern handheld devices need multiband usable features such as Bluetooth, Wi-Fi, Wi-MAX, etc., which are being integrated into a single mechanism $[8,9]$.

The system efficiency of a multiple antenna system can be largely improved by increasing the number of antennas in the terminals of transmitters and receivers. The within element isolation of the multiple antenna system is poor because of the close arrangement of antenna elements, thereby causing deterioration of overall design efficiency [10-12]. Thus, the improvement of inter-element isolation of the antenna system is challenging for multiple antenna design technology on the same substrate. With the rising need for a larger capacity of the MIMO communication system, the concern of the inter-element isolation improvement of the two and four-element antenna systems has gained tremendous consideration [13-15].

In this regard, numerous two and four element antenna are discussed in the literature [16-23]. In [16] the author designed a two element MIMO antenna by utilizing an 
inverted $\mathrm{T}$ and $\mathrm{E}$-shaped radiator, wherein the isolation is improved by including a parasitic resonator between the elements. However, the achieved mutual coupling reduction is only around $20 \mathrm{~dB}$. A compact quad element MIMO antenna with a split ring resonator as the radiating part is proposed in [17]. The four element is placed orthogonal to each other to improve the isolation. However, the isolation achieved by such configuration is only $14 \mathrm{~dB}$ which is generally less for a MIMO system. In [18] a quad element wideband MIMO antenna is proposed. The isolation in the overall MIMO structure is achieved by placing the asymmetric monopole in orthogonal orientation. However, the achieved isolation is only $20 \mathrm{~dB}$ and at the same time, the overall antenna dimension is large. In [19] a four element L-shaped monopole dual-band antenna loaded with complementary split-ring resonator for MIMO application is proposed. However, the achieved isolation is less and the size of the antenna is considerably large. A four port MIMO patch antenna utilizing a square ring-shaped radiator and the complementary split-ring resonator is proposed in [20] for achieving high isolation. However, the achieved isolation is only $22 \mathrm{~dB}$ and the size of the antenna is large. In [21] a four port Koch fractal four port MIMO antenna based on the parasitic resonator is proposed. The antenna exhibits good diversity parameters. However, the achieved isolation is around $20 \mathrm{~dB}$ and the size of the antenna is considerably large. Similarly, the MIMO structure proposed in [22, 23, 29-34] shows isolation around $17 \mathrm{~dB}$ and is large in size. However, the presented two and four port antenna in this paper removes the drawback of less isolation and large size as discussed in [16-23, 29-34]. The proposed structure serves twofold advantage over the aforementioned literature.

1. The two and four port element antenna achieves high isolation (i.e., greater than $25 \mathrm{~dB}$ ) without utilizing any decoupling methods, thus, totally benefits from the monopole asymmetrical structure.

2. It achieves better diversity performances as compared to the antenna discussed in [16-23, 29-34].

In this research paper, a wideband CPW fed antenna operating from 4.3 to $6.45 \mathrm{GHz}$ is developed on a FR4 substrate. Using this antenna, a study towards the two and four element structure is carried out by analysing the performance parameters of the multiple antennas placed and inter-element interferences. The proposed design serves three fold novelty, they are (1) the applied feeding technique (i.e., $\mathrm{CPW}$ ) enables the antenna design on the single side of the substrate thereby making integration easier with the monololithic integrated microwave circuit (MMIC),
(2) the slotted radiating patch provides good impedance matching as well improves the bandwidth considerably, as compared to normal microstrip patch antenna, (3) the orientation of the two and four element antenna is in best interest to have optimum isolation, thereby avoiding the usage of any decoupling structure thus, helps in achieving a simple planar configuration. The entire simulations are performed using the EM simulator ANSYS HFSS v.14.0 and the optimized design is fabricated to test the operating parameters.

\section{Antenna design}

This section describes the designing of a single wideband monopole antenna and its evolution into the proposed two and four antenna element MIMO configuration.

\subsection{Single element antenna}

A CPW fed antenna is optimized to obtain a wide bandwidth operating from 4.30 to $6.45 \mathrm{GHz}(2150 \mathrm{MHz})$. A single side design has a lower cost of fabrication with a reduced material cost. The wide bandwidth in the antenna is accomplished using a split shaped radiating patch as depicted in Fig. 1a. The slotted radiating patch affects the flow of surface current which in turn increases the total current flow path thereby tends the design to exhibit wide bandwidth. The corresponding reflection coefficient $\left(S_{11}\right)$ which is as low as $-33.5 \mathrm{~dB}$ at the center frequency of $5.2 \mathrm{GHz}$ as seen in Fig. 2b. Table 1, details the overall design dimensions of the antenna.

\subsection{Two element antenna design}

A two port antenna design is developed by placing the antenna elements on both the side of the substrate material having a dimension of $20 \times 45 \mathrm{~mm}^{2}$. To have good isolation between the antenna elements, the second element's orientation is varied as seen in Fig. 2a as 'Antenna 1' and 'Antenna 2 '. The corresponding isolation and reflection coefficient is depicted in Fig. 2b. It is observed from Fig. 2b that the isolation between the antenna elements is greatly increased to $-30 \mathrm{~dB}$ just by rotating any one element by $90^{\circ}$, as also studied in [24].

The distribution of surface current at one of the frequency say $5.5 \mathrm{GHz}$ (at port 1-2) is explained in Fig. 3. It is evident from the figure that more current distribution is noticed at port 1 when this port is excited by keeping port 2 at the matched condition or vice-versa. Also, it can be noticed that there is an opposite flow of current, thereby suppressing 


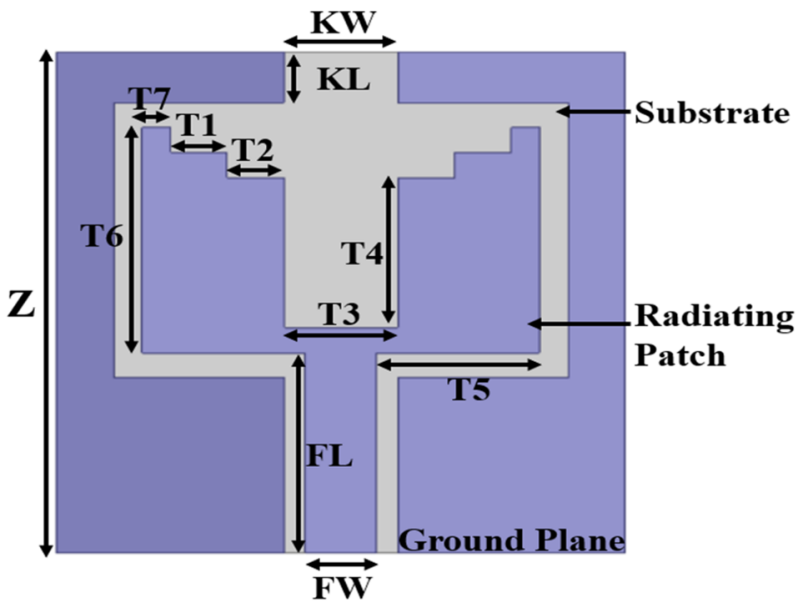

(a)

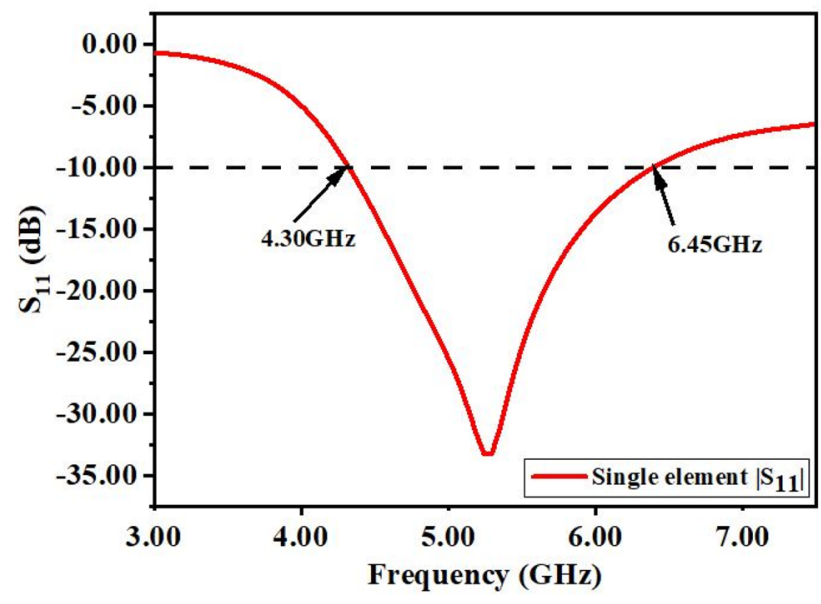

(b)

Fig. 1 a Wide band antenna structure. b Reflection coefficient of the proposed single element

the flow of current to the adjacent element which in turn increases the isolation. [Note: We have taken one frequency over the entire bandwidth to explain the current behavior, because the phenomenon will be the same at other frequencies also].

\subsection{Four element antenna design}

The proposed four element configuration is designed to maximize the number of inputs while minimizing interference. This results in a design, where there are antennas on both the planes of the configuration. There are two possible configurations for the required conditions as depicted in Fig. 4a, b. Figure 4a shows 'Configuration 1' and Fig. 4b shows 'Configuration 2'. Figure 5 shows isolation characteristics for the two configurations and it is quite evident from that 'Configuration 2' has far better isolation characteristics

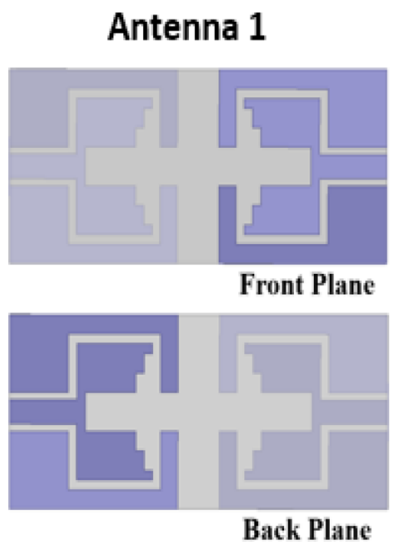

Antenna 2

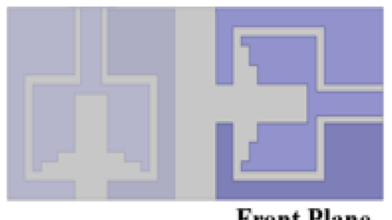

Front Plane

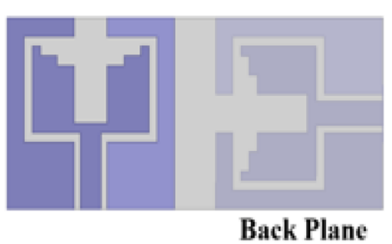

(a)

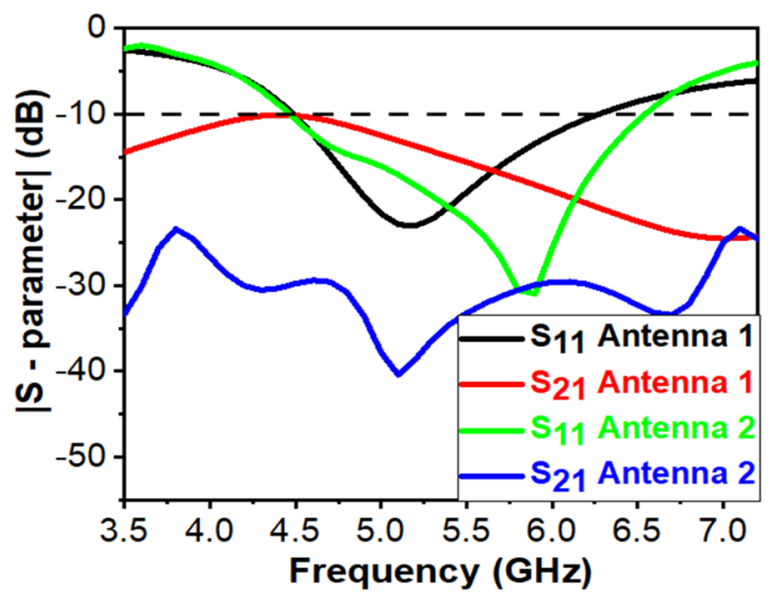

(b)

Fig. 2 a Two element MIMO design configurations. b Corresponding |S-parameters $\mid$

Table 1 Detailed dimensional parameters

\begin{tabular}{ll}
\hline Parameter & $\begin{array}{l}\text { Dimen- } \\
\text { sions } \\
(\mathrm{mm})\end{array}$ \\
\hline FW & 2 \\
KL & 4 \\
Z & 20 \\
FL & 4 \\
KW & 4 \\
T7 & 1 \\
T6 & 9 \\
T5 & 5.75 \\
T4 & 6 \\
T3 & 4 \\
T2 & 2 \\
T1 & 2 \\
\hline
\end{tabular}


Fig. 3 Surface current pattern at a Port 1 and $\mathbf{b}$ Port 2
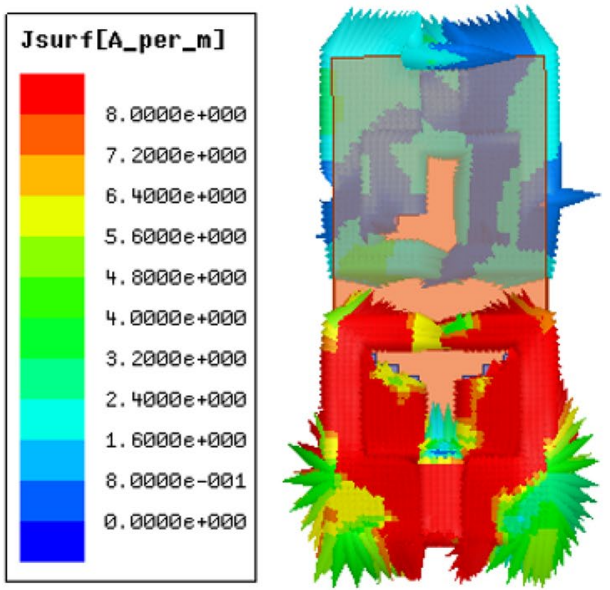

(a)

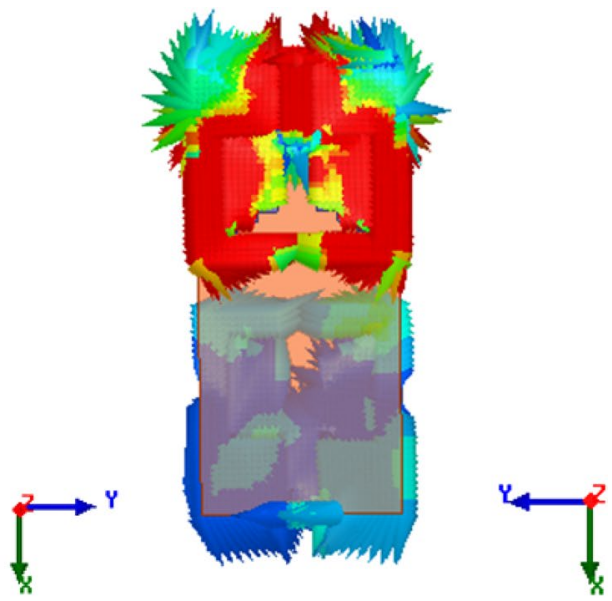

(b)
Fig. 4 Possible configurations of the proposed four element antenna a configuration $1, \mathbf{b}$ configuration 2

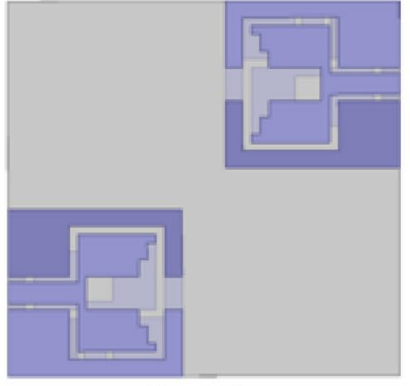

Front Plane

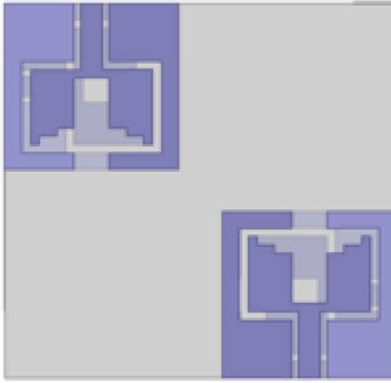

Back Plane

\section{Configuration 1}

(a)

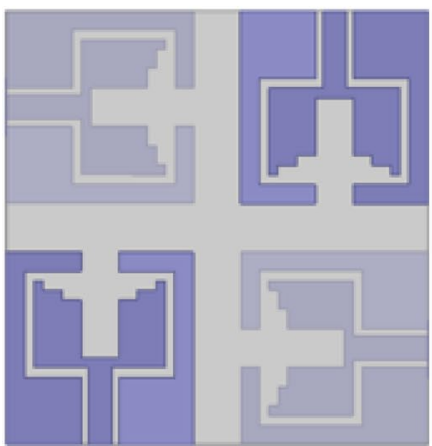

Front Plane

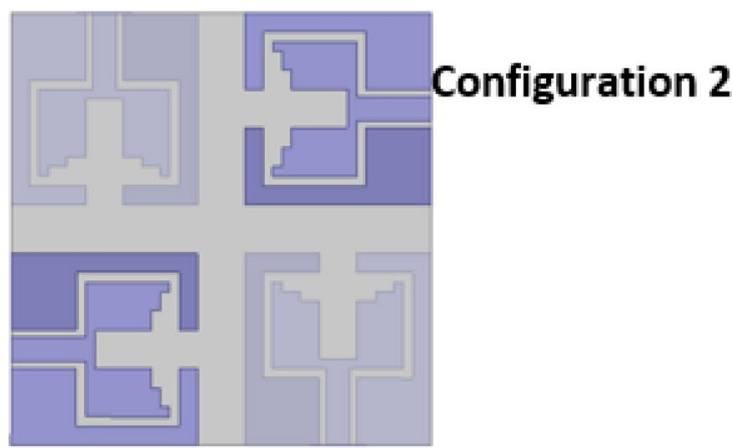

Back Plane (b) than 'Configuration 1' due to the distinct spacing between the antenna elements. The final configuration is presented in Fig. 6 and Table 2 contains its specific dimensional parameters. The proposed configuration has a compact size with improved isolation between the antenna elements.

\subsubsection{Parametric study of the four element}

Parametric analysis is performed to analyze the effect of a dimension on the overall performance of the antenna. In this paper, this involves the analysis of return loss as well as isolation characteristics. The first parameter to be analyzed 


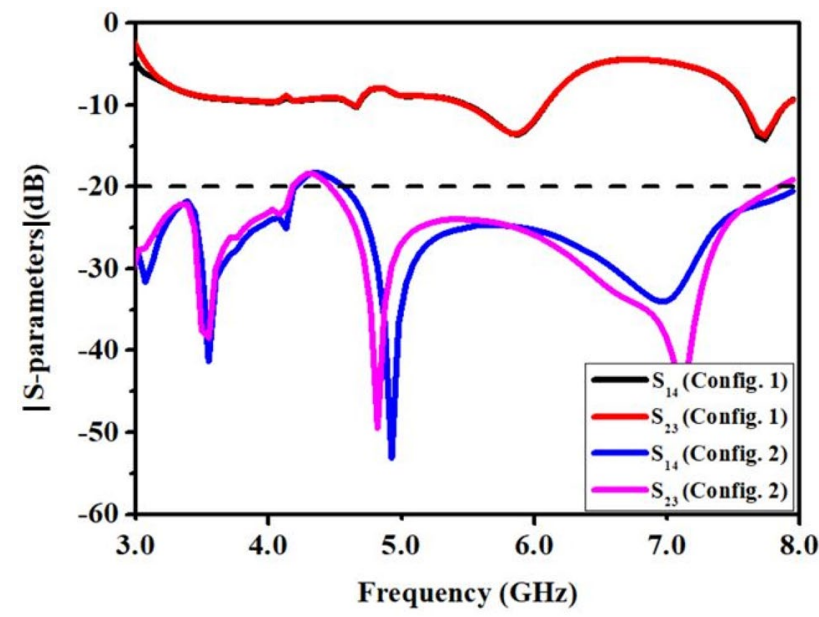

Fig. 5 Isolation characteristics of the two configurations

is the width of the feedline (FW) of the four antennas of the proposed configuration. Figure 7 shows the results for parametric analysis for 'Antenna 1'. It is quite evident from the graph that $\mathrm{FW}=2 \mathrm{~mm}$ gives the best return loss and $-10 \mathrm{~dB}$ bandwidth.

A similar analysis for 'Antenna 2' is carried out and similar observations as in the case of the previous antenna are made. Figure 8 gives the results for the analysis.

For 'Antenna 3' the width of FW increased till the performance starts deteriorating. The change in performance occurs at $\mathrm{FW}=2 \mathrm{~mm}$. Figure 9 gives the result of the parametric analysis performed.

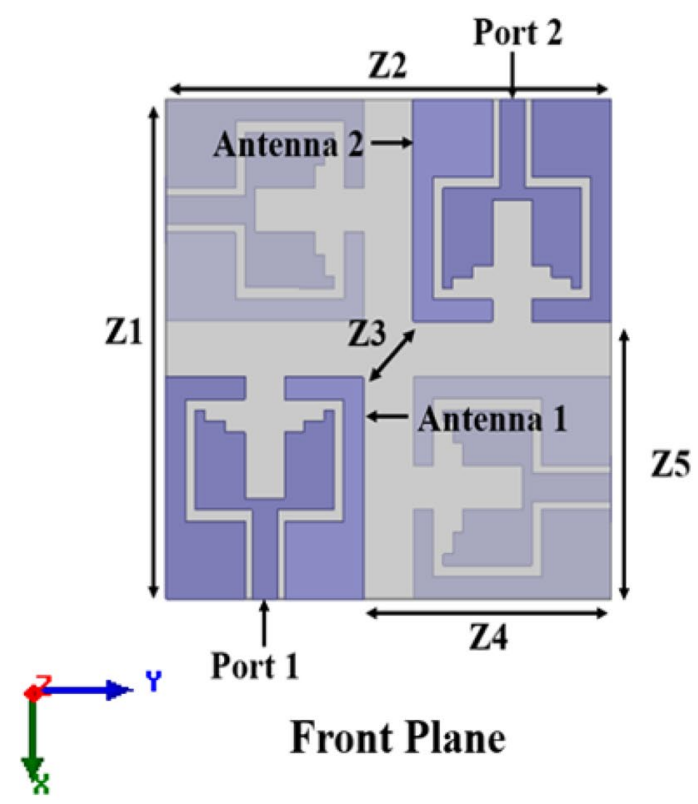

Table 2 Dimensional parameters of the configuration

\begin{tabular}{ll}
\hline Parameter & $\begin{array}{l}\text { Dimen- } \\
\text { sions } \\
(\mathrm{mm})\end{array}$ \\
\hline $\mathrm{Z1}$ & 45 \\
& 45 \\
$\mathrm{Z3}$ & 7.071 \\
$\mathrm{Z4}$ & 25 \\
$\mathrm{Z5}$ & 25 \\
$\mathrm{Z6}$ & 7.071 \\
$\mathrm{Z7}$ & 25 \\
$\mathrm{Z8}$ & 25 \\
\hline
\end{tabular}

Similarly, analysis for 'Antenna 4' is carried out. Return loss for acceptable $-10 \mathrm{~dB}$ bandwidth is observed when $\mathrm{FW}=2 \mathrm{~mm}$. Figure 10 shows the results of the analysis.

A similar parametric analysis is carried out for another parameter T3. Figure 11 shows the results for parametric analysis for T3 for 'Antenna 1'. Although T3 $=2 \mathrm{~mm}$ gives better return loss, but $\mathrm{T} 3=4 \mathrm{~mm}$ is chosen, because it has better $-10 \mathrm{~dB}$ bandwidth.

Similarly, analysis for 'Antenna 2' is carried out, the results are shown in Fig. 12. It is visible from the results that $\mathrm{T} 3=4 \mathrm{~mm}$ is chosen, because it is giving the lowest return loss while maintaining the largest $-10 \mathrm{~dB}$ bandwidth.

Analysis for 'Antenna 3' leads to similar observations as made in the previous one. $\mathrm{T} 3=4 \mathrm{~mm}$ gives better return loss than $\mathrm{T} 3=6 \mathrm{~mm}$ and better $-10 \mathrm{~dB}$ bandwidth than $\mathrm{T} 3=2 \mathrm{~mm}$. Figure 13 shows the results of the analysis.

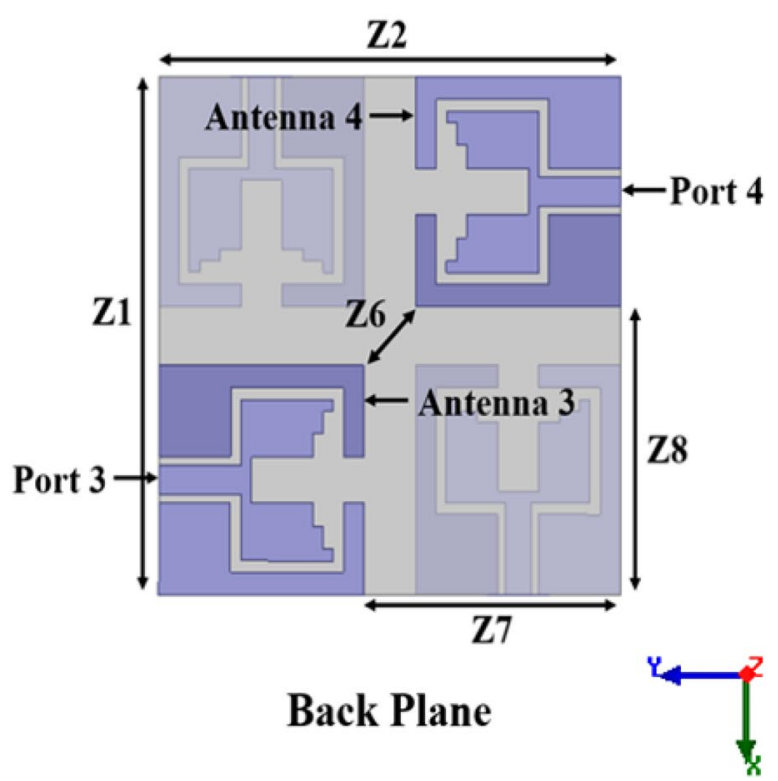

Fig. 6 Final configuration of the four element antenna 


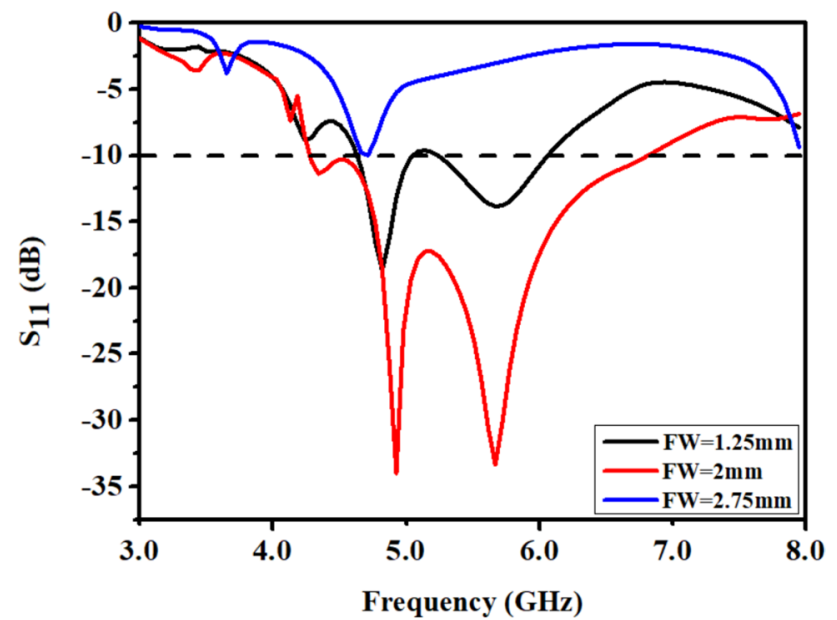

Fig. 7 Analysis of FW for antenna 1

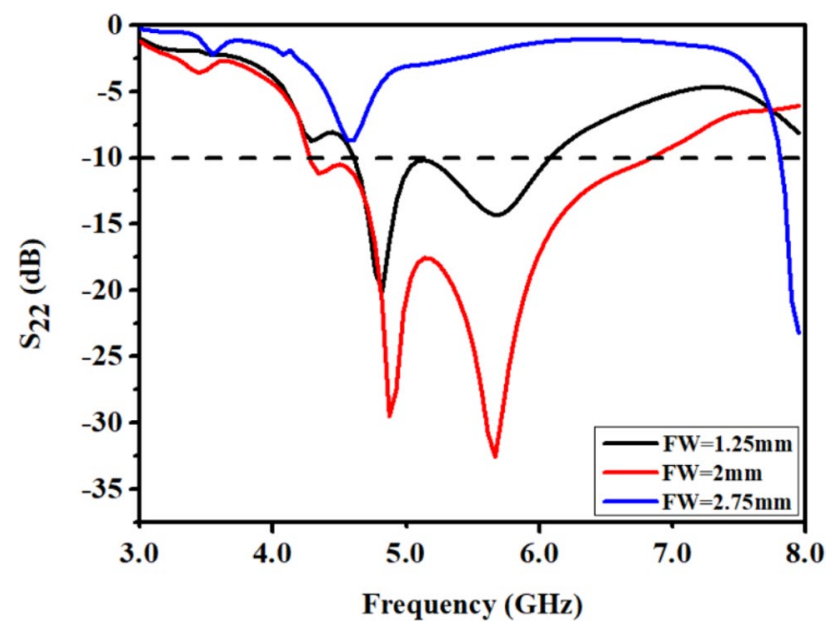

Fig. 8 Analysis of FW for antenna 2

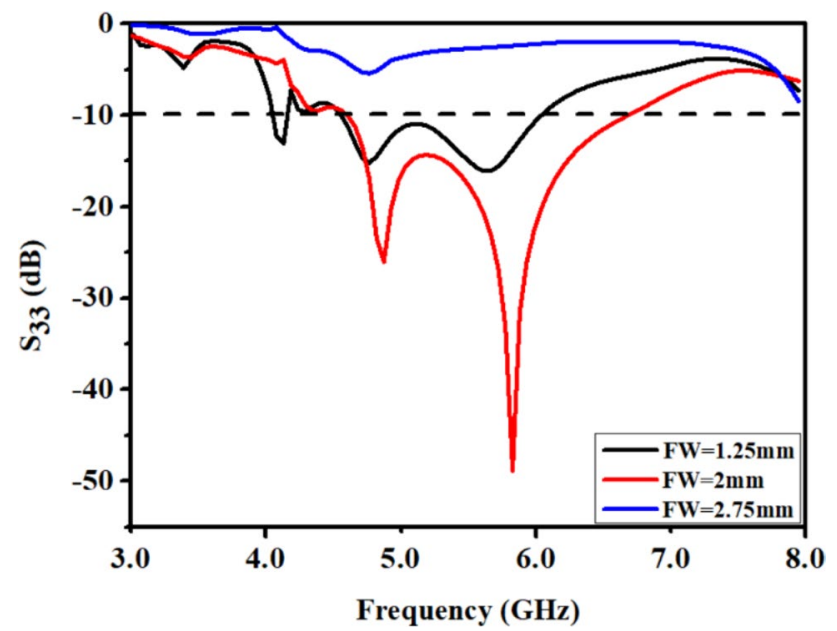

Fig. 9 Analysis of FW for antenna 3

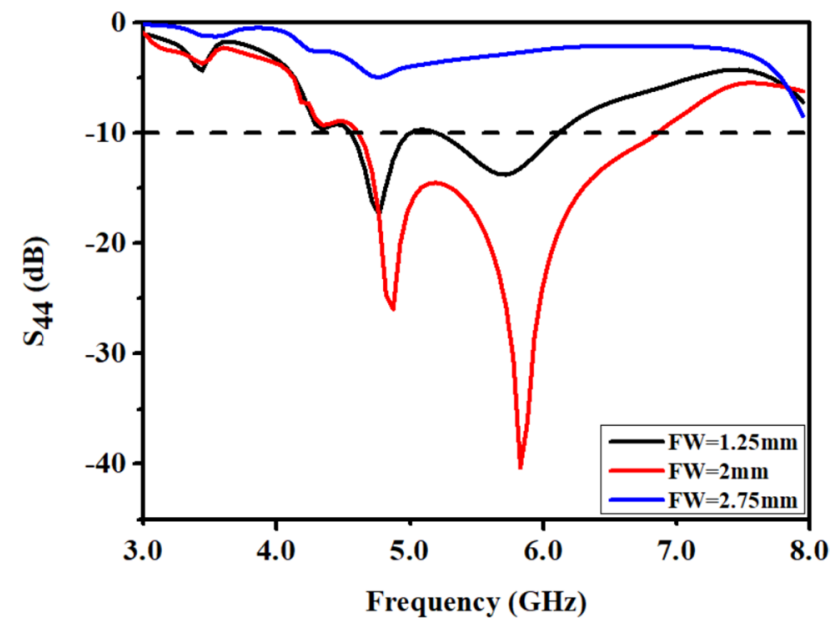

Fig. 10 Analysis of FW for antenna 4

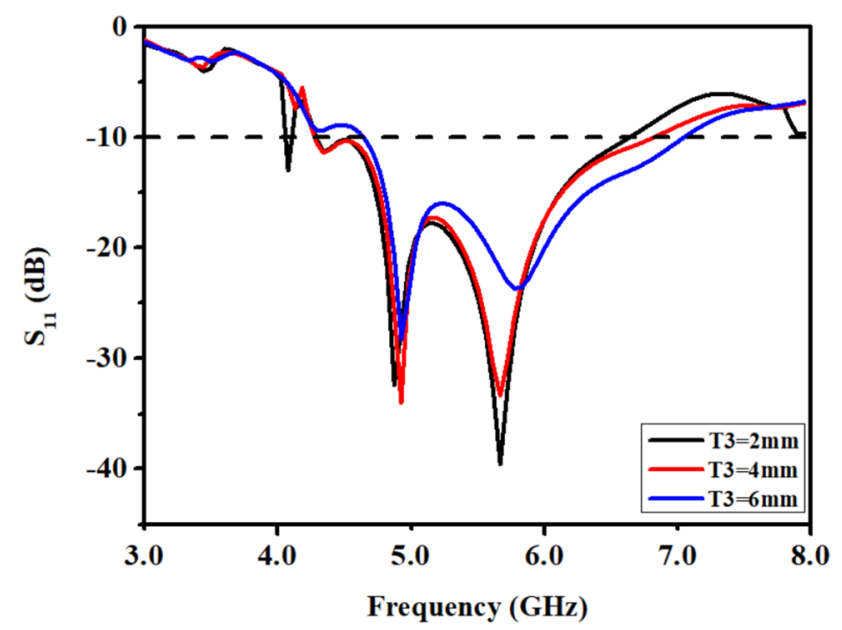

Fig. 11 Analysis of T3 for antenna 1

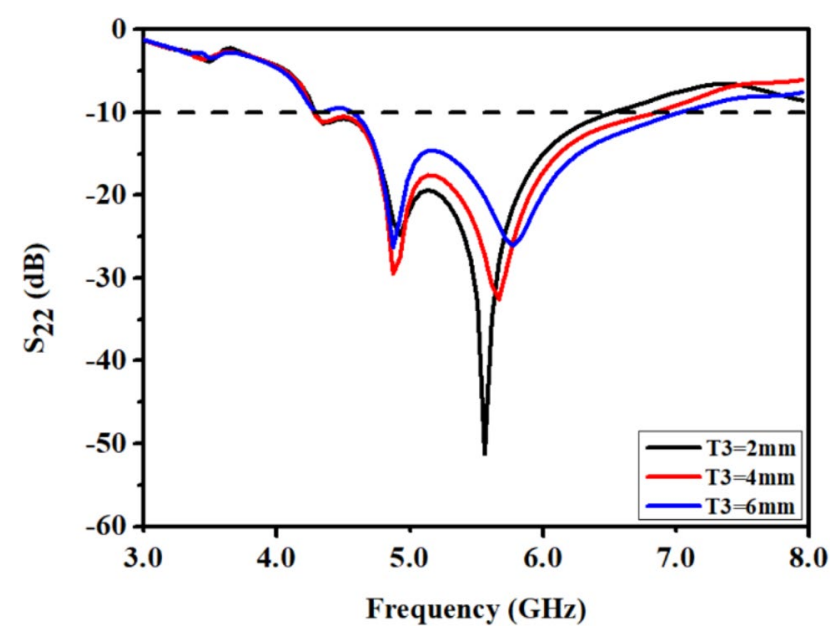

Fig. 12 Analysis of T3 for antenna 2 


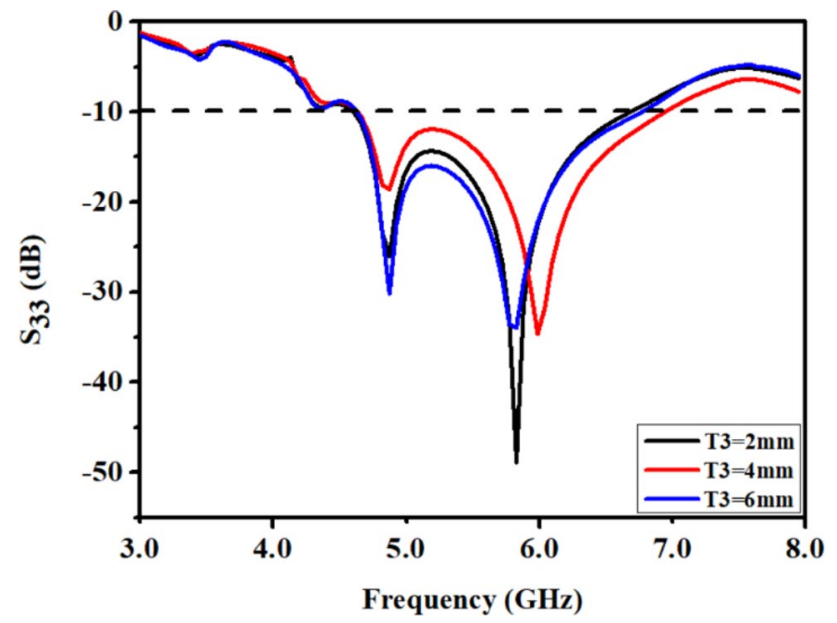

Fig. 13 Analysis of T3 for antenna 3

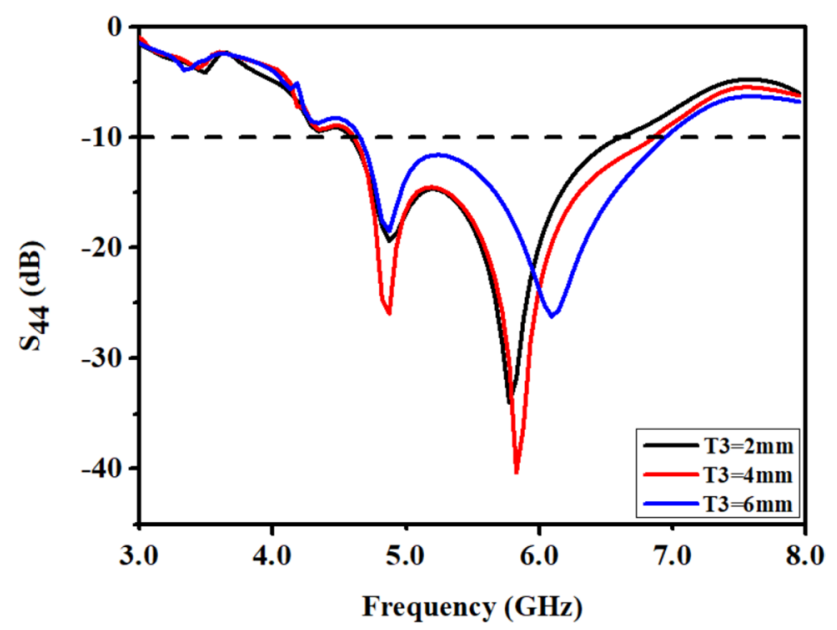

Fig. 14 Analysis of T3 for antenna 3

A similar analysis is carried for 'Antenna 4', the results of the analysis are depicted in Fig. 14. It can be inferred from the graph that $\mathrm{T} 3=4 \mathrm{~mm}$ gives the best bandwidth while maintaining appreciable return loss.

After parametric analysis for return loss, another analysis for the isolation characteristics which play a vital role in a multiple antenna configuration is done and is depicted in Figs. 15 and 16. For isolation characteristics, the optimum value of $\mathrm{Z} 3$ on the front plane of the configuration is calculated. During the analysis, it is observed that the wide operational bandwidth of all the antennas decreased and the wide operational band of 'Antenna 4' became dual. Figure 15 shows the results of the analysis. It is visible from the graph that only $\mathrm{Z} 3=7.07 \mathrm{~mm}$ has a return loss of less than $-20 \mathrm{~dB}$ for the entire bandwidth.

Similarly, analysis is performed for antennas on the back plane of the antenna. Figure 16 shows the variation of $S_{34}$

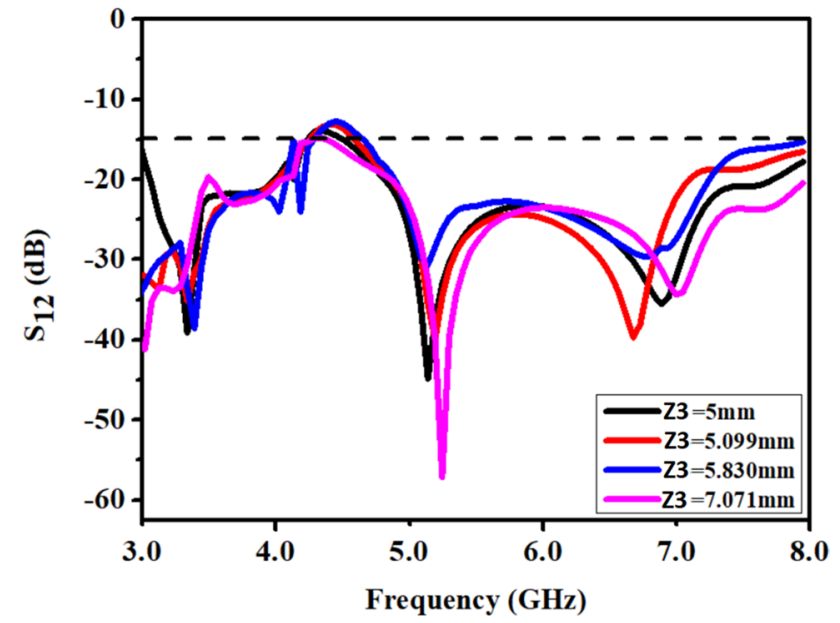

Fig. 15 Isolation characteristics analysis for the front plane adjacent element distance Z3

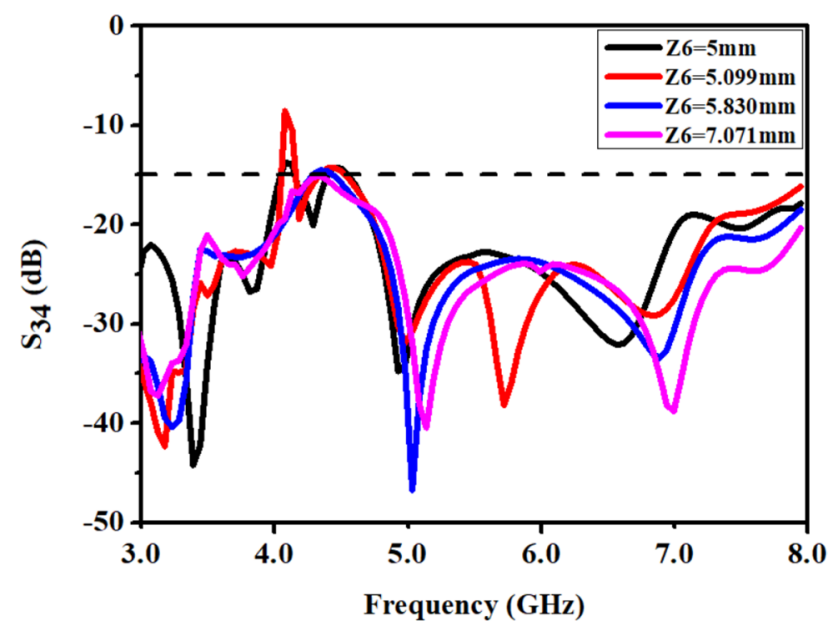

Fig. 16 Isolation characteristics analysis for the front plane adjacent element distance Z6

with variations in Z6. It is evident from the graph that only $\mathrm{Z} 6=7.07 \mathrm{~mm}$ stays below the $-20 \mathrm{~dB}$.

\subsubsection{Current distribution}

The distribution of surface current at one of the frequency say $5.5 \mathrm{GHz}$ (at port 1-4) is explained in Fig. 17. It is evident from Fig. 17a that more current distribution is noticed at port 1 when this port is excited by keeping port 2 , port 3 , and port 4 at the matched condition or vice-versa. The basic principle which governs here to suppress the mutual coupling is to place the antenna in orthogonal orientation in both the front and back plane. By doing so it is evident from the figure that there is a field cancellation between the orthogonally spaced elements (both in front and back 


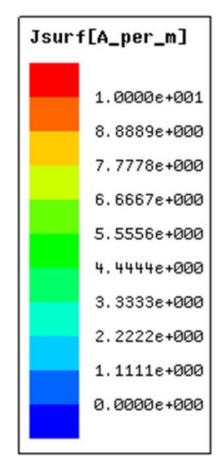

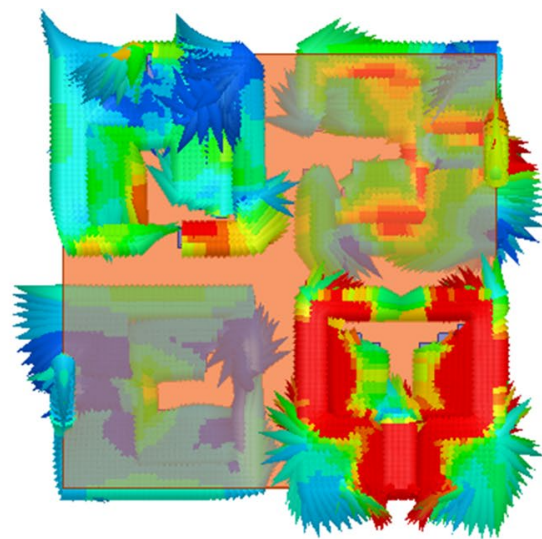

(a)

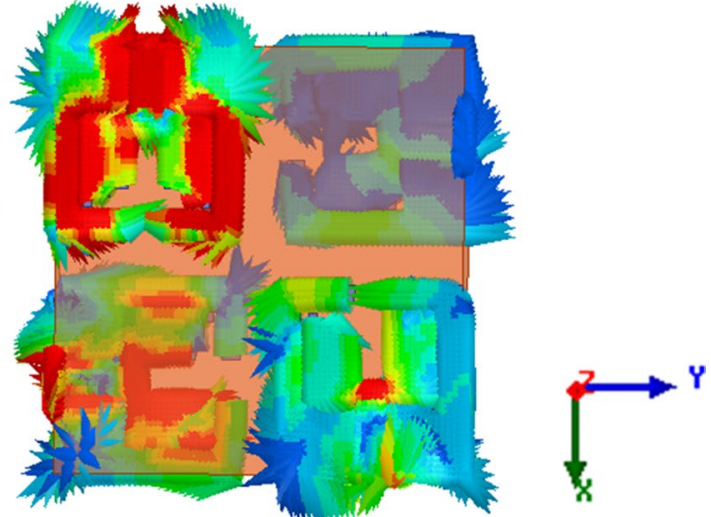

(b)

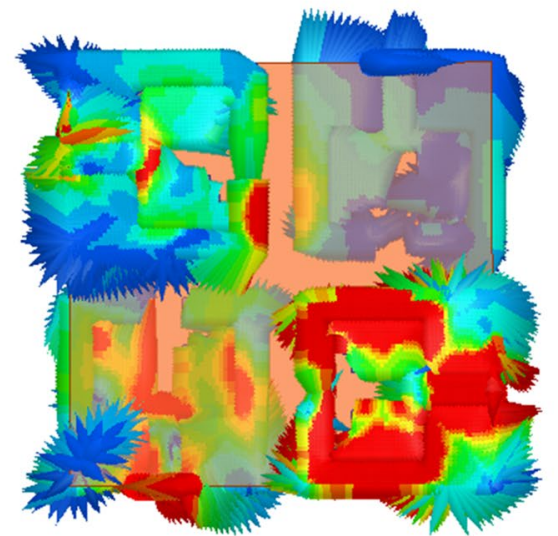

(c)
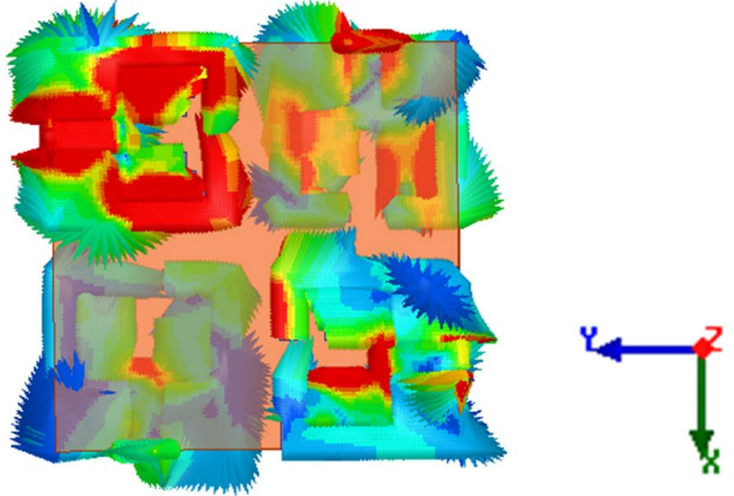

(d)

Fig. 17 Surface current pattern at a Port, b Port 2, c Port 3 and d Port 4

plane) that decouples the current between the elements. As a result of this field cancellation, the proposed design impedance characteristics change thereby improving the isolation between the antenna elements. The current flow from the ground part to the antenna is opposite in nature. This suppresses the flow of current to the adjacent element. The same can be observed at port 2 , port 3 , and port 4 depicted in Fig. 17b-d, respectively.

\section{Results and discussion}

The proposed two element and four element antennas with the best isolation design are analyzed in Ansys HFSS. The prototype of the proposed designs is fabricated on FR4 substrate with $1.6 \mathrm{~mm}$ thickness, 4.4 dielectric constant, and 0.02 loss tangent as illustrated in Fig. 18 for further practical analysis.
The simulated and measured $\mid S$-parameters $\mid$ of the two element antenna at both the ports are depicted in Fig. 19. It can be seen that at port 1 , the $-10 \mathrm{~dB}$ bandwidth ranges from 4.71 to $6.62 \mathrm{GHz}$ and the transmission coefficient is well below $-30 \mathrm{~dB}$ in simulation. The measured results are also in good agreement, where the $-10 \mathrm{~dB}$ bandwidth ranges from 4.89 to $6.66 \mathrm{GHz}$ and the transmission coefficient is well below $-20 \mathrm{~dB}$. Similarly, at port 2 , the $-10 \mathrm{~dB}$ bandwidth ranges from 4.44 to $6.58 \mathrm{GHz}$ and the transmission coefficient is well below $-30 \mathrm{~dB}$ in simulation. The measured results are also in a good agreement, where the $-10 \mathrm{~dB}$ bandwidth ranges from 4.67 to $6.35 \mathrm{GHz}$ and the transmission coefficient is well below $-20 \mathrm{~dB}$.

The simulated and measured $\mid S$-parameters $\mid$ of the four element antenna design at port 1 are depicted in Fig. 20. The observed frequency range and $I S$-parameterl coefficient magnitude is summarized in Table 3. The fabricated prototype of two and four elements exhibits slightly deviated results from 


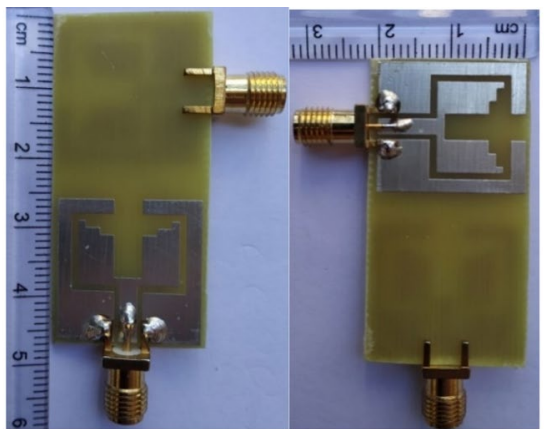

(a)

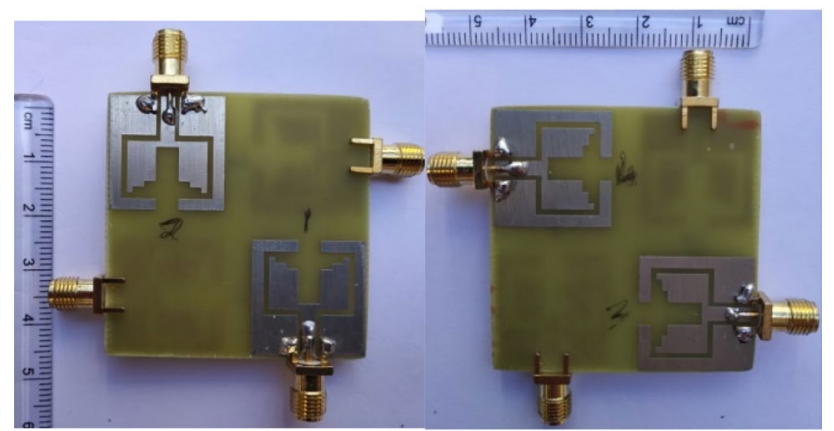

(b)

Fig. 18 a Fabricated two element design front and back part. b Fabricated four element design front and back part simulation which may be due to split shaped patch and the asymmetric orientation of antenna elements which is used to enhance the isolation between the antenna elements. Also, this difference may be due to the misalignment of SMA connector with feedline, substrate dielectric constant variation at higher frequency, fabrication tolerance and measurement facility, primary due to antenna mounting and positioning system in the laboratory.

The various diversity parameters which state the acceptable performance of the proposed two and four element antenna such as Envelope Correlation Coefficient (ECC), Diversity Gain (DG), Total Active Reflection Coefficient (TARC), Mean Effective Gain (MEG) and Channel Capacity Loss (CCL) are also studied and detailed below.

The ECC states how multiple antennas in a system are independent in its radiation pattern. The ECC between the antennas elements are calculated using [25]. Basically, ECC tells the correlation between the radiating elements. It provides a measure of correlation in the radiation pattern of $m$ th radiating element with $n$th radiating element in a given antenna system. It can be noted that most of the planar antennas suffer from loss, so the use of $S$-parameters are generally avoided in the calculation of ECC parameter. Thus for wideband antennas, to compute ECC, far-field pattern is preferred and is given by Eq. (1):

$\mathrm{ECC}_{n m}=\frac{\left|\int_{0}^{2 \pi} \int_{0}^{\pi}\left(E_{\theta m}^{*} E_{\theta n} P_{\theta} \cdot X P R+E_{\varphi m}^{*} E_{\varphi n} P_{\varphi}\right) \mathrm{d} \Omega\right|^{2}}{\int_{0}^{2 \pi} \int_{0}^{\pi}\left(E_{\theta n}^{*} E_{\theta n} P_{\theta} \cdot X P R+E_{\varphi n}^{*} E_{\varphi n} P_{\varphi}\right) \mathrm{d} \Omega+\int_{0}^{2 \pi} \int_{0}^{\pi}\left(E_{\theta m}^{*} E_{\theta m} P_{\theta} \cdot X P R+E_{\varphi n}^{*} E_{\varphi n} P_{\varphi}\right) d \Omega}$,

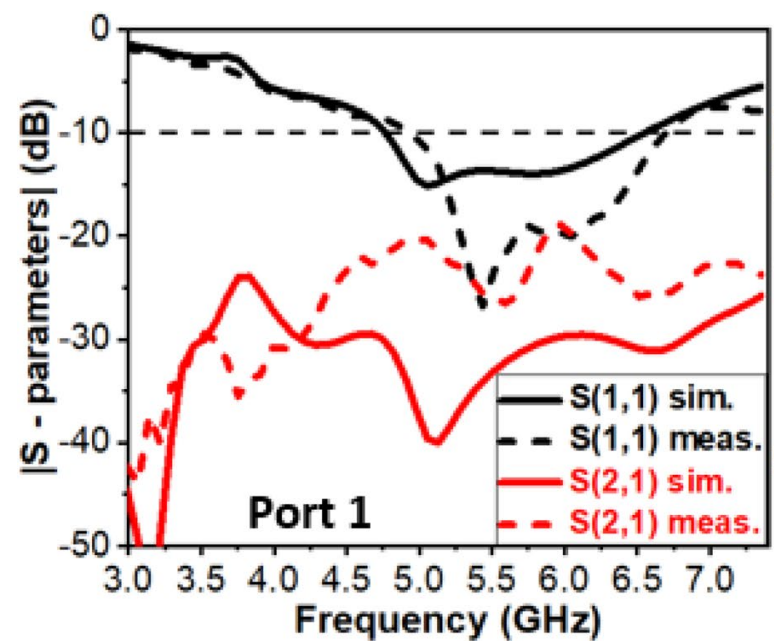

Fig. 19 Simulated and measured $\mid S$-parametersl at port 1 and port 2 of two element model 


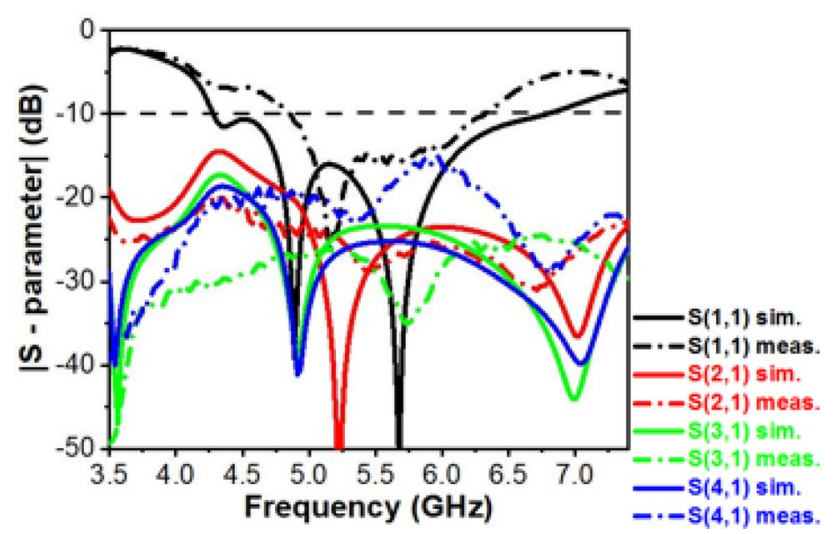

Fig. 20 Comparison between simulated and measured $\mid S$-parameters $\mid$ at port 1

where XPR is the cross-polarization rate and is defined as the ratio of average power along $\varphi\left(P_{\mathrm{H}}\right)$ and $\theta\left(P_{\mathrm{V}}\right)$ coordinates. $E_{\varphi m}$ and $E_{\theta n}$ are the complex envelope along $\varphi$ and $\theta$ direction. Ideally, ECC has to be 0 , and in a practical environment, the acceptable limit of ECC is less than 0.5 $(\mathrm{ECC}<0.5)$. The ECC curves for the designed antenna are depicted in Fig. 21, wherein it can be seen that ECC values are well below the required limit. In Fig. 21a, the ECC calculated for the two element design is depicted. Similarly, in Fig. $21 \mathrm{~b}$ the ECC for the four element design between adjacent and diagonal ports is calculated.

To have good quality and reliability in wireless systems, the DG of the multiple antenna design has to be high, nearly $10 \mathrm{~dB}$ in the operating bandwidth. The DG is calculated from the ECC value using the Eq. (2). The DG of the proposed two and four port antenna structure is illustrated in Fig. 22. It can be observed that the DG of the antenna in the entire operating range is around $10 \mathrm{~dB}$ :

$\mathrm{DG}=10 \times \sqrt{1-\left|\mathrm{ECC}_{n m}\right|^{2}}$.

The TARC is defined as the ratio between the square root of total reflected power to the square root of total incident power. The generalized TARC for $\mathrm{N}$ port antenna and for the case of $2 \times 2$ antenna array is calculated from the below Eqs. (3-4), respectively [26, 27]:
Table 3 Performance of the proposed design

\begin{tabular}{lllll}
\hline Port no. & $\begin{array}{l}-10 \mathrm{~dB} \text { bandwidth } \\
\operatorname{sim}(\mathrm{GHz})\end{array}$ & $\begin{array}{l}-10 \mathrm{~dB} \text { bandwidth } \\
\text { meas. }(\mathrm{GHz})\end{array}$ & $\begin{array}{l}\text { Transmission coef- } \\
\text { ficient sim. }(\mathrm{dB})\end{array}$ & $\begin{array}{l}\text { Transmission coef- } \\
\text { ficient meas. }(\mathrm{dB})\end{array}$ \\
\hline 1 & $4.26-6.82$ & $4.84-6.33$ & $<-25$ & $<-15$ \\
2 & $4.28-6.78$ & $4.86-6.98$ & $<-25$ & $<-20$ \\
3 & $4.53-6.82$ & $4.14-6.69$ & $<-25$ & $<-20$ \\
4 & $4.55-6.87$ & $4.32-6.94$ & $<-25$ & $<-20$ \\
\hline
\end{tabular}

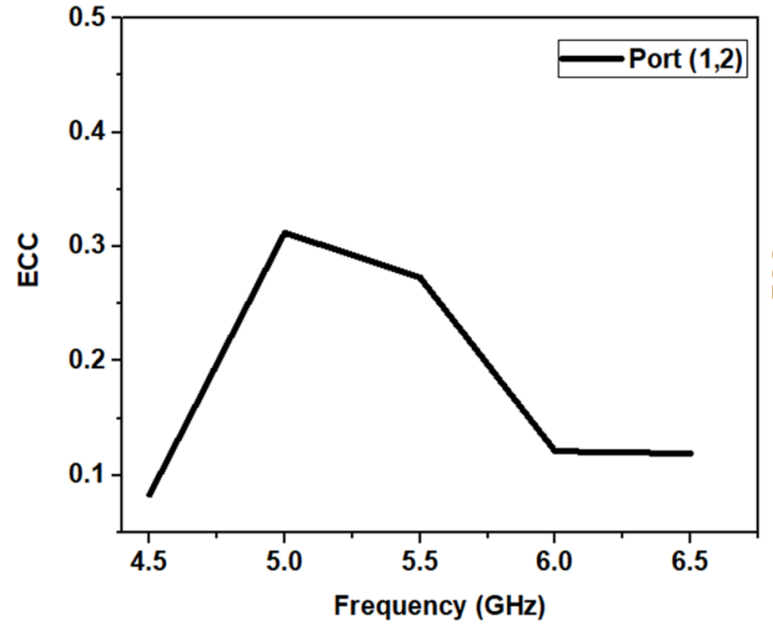

(a)

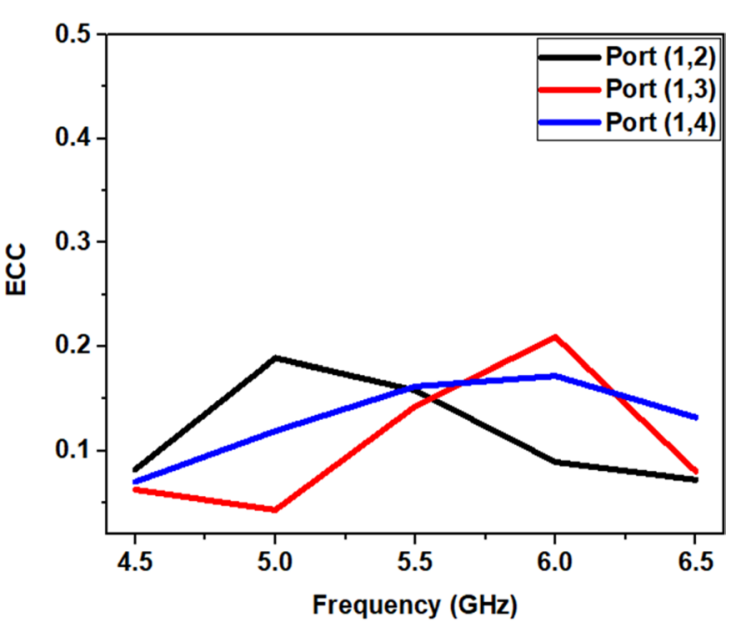

(b)

Fig. 21 ECC of the proposed structure for a two element, $\mathbf{b}$ four element 


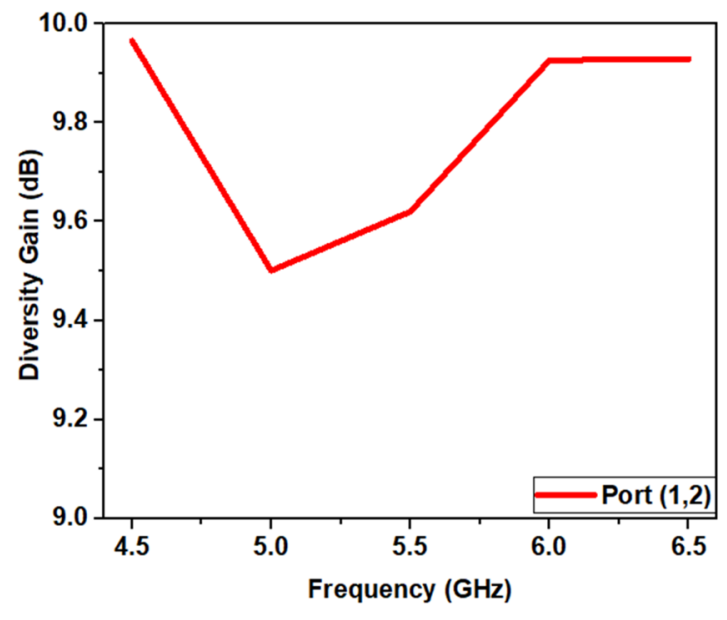

(a)

Fig. 22 DG for the proposed a two element, $\mathbf{b}$ four element

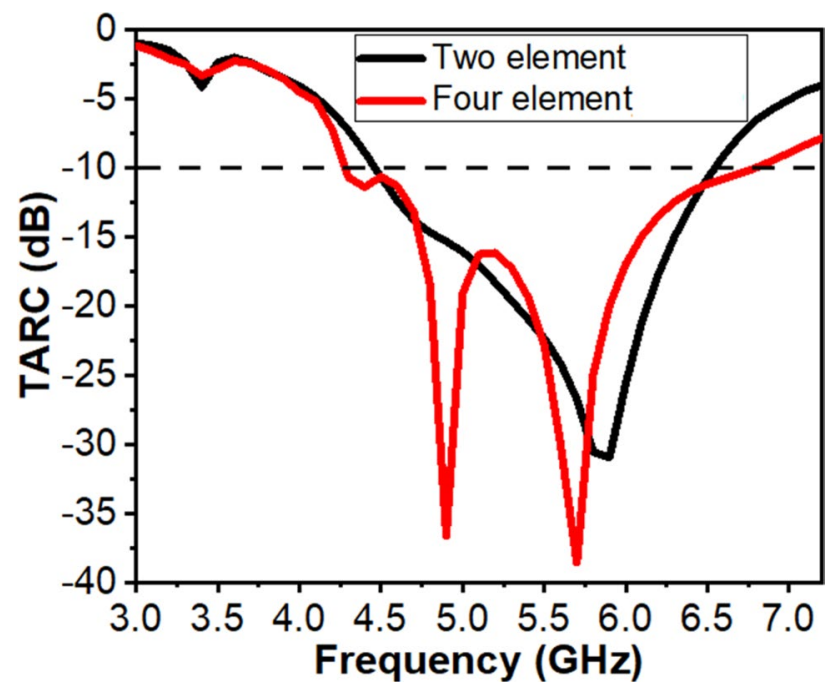

Fig. 23 TARC of the proposed two and four element MIMO design

$$
\begin{aligned}
\Gamma_{a}^{t} & =\frac{\sqrt{\sum_{i=1}^{N}\left|b_{i}\right|^{2}}}{\sqrt{\sum_{i=1}^{N}\left|a_{i}\right|^{2}}} \\
\Gamma_{a}^{t} & =\frac{\sqrt{\left(\left|\left(s_{11}+s_{12}^{j \theta}\right)\right|^{2}+\left|\left(s_{21}+s_{22}^{e j \theta}\right)\right|^{2}\right)}}{\sqrt{2}},
\end{aligned}
$$

where $b_{i}=[s] \cdot a_{i} \cdot[s]$ is the scattering matrix of the multiple antenna, $[b] \rightarrow$ scattering vector and $[a] \rightarrow$ excitation vector. For $\mathrm{N}$ port antenna, TARC is related to total incident power

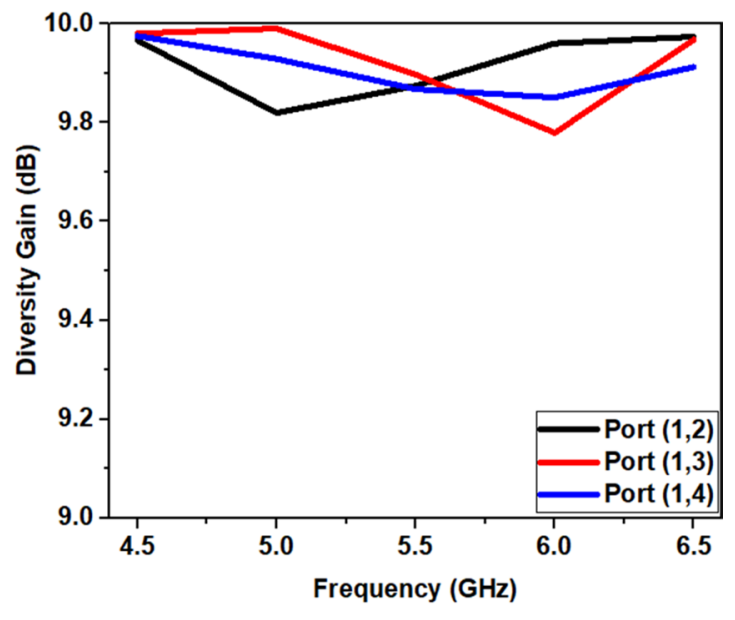

(b)

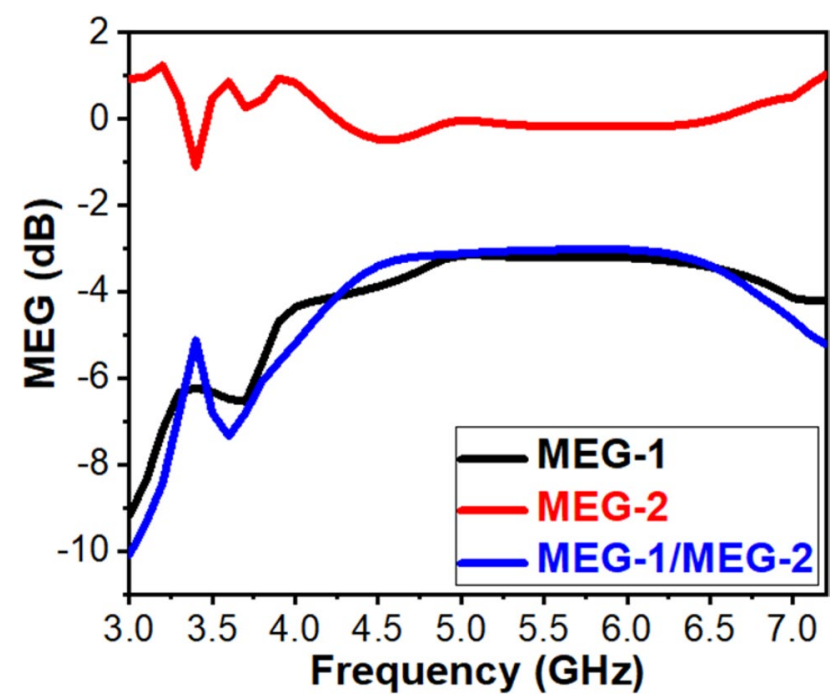

Fig. 24 MEG analysis between the ports of two element antenna

to total outgoing power. Ideally, it has to be zero which means all the power delivered is accepted by the antenna. The calculated result of the proposed two and four element design is illustrated in Fig. 23.

The MEG is an important parameter in multiple antenna design analysis and is defined as the ratio of power received by diversity antenna to power received by an isotropic antenna. The MEG analysis for the proposed two element antenna is done at port 1 and port 2 as depicted in Fig. 24. In the same manner, for the proposed four element antenna MEG analysis is also done between port 1 and port 2, port 1 and port 3 and port 2 and port 4 as shown in Fig. 25. For a good multiple antenna design with the same power level, the 


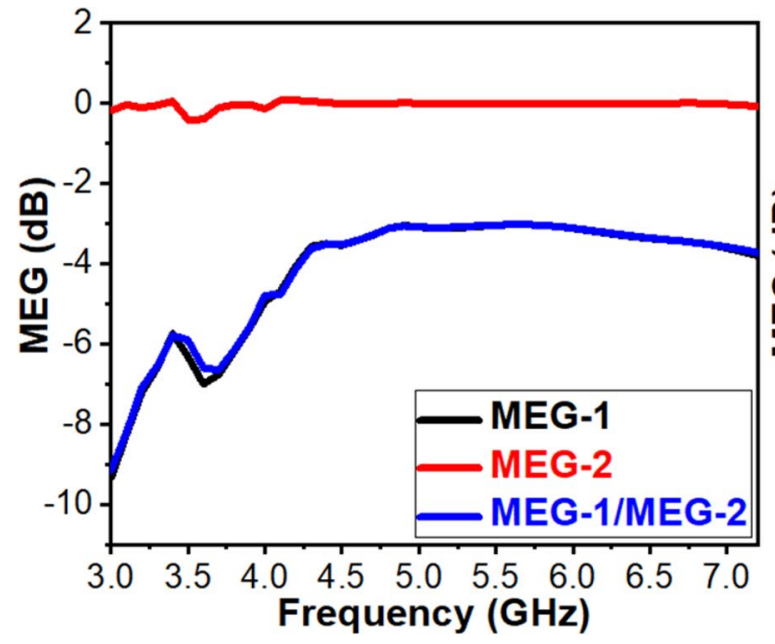

(a)

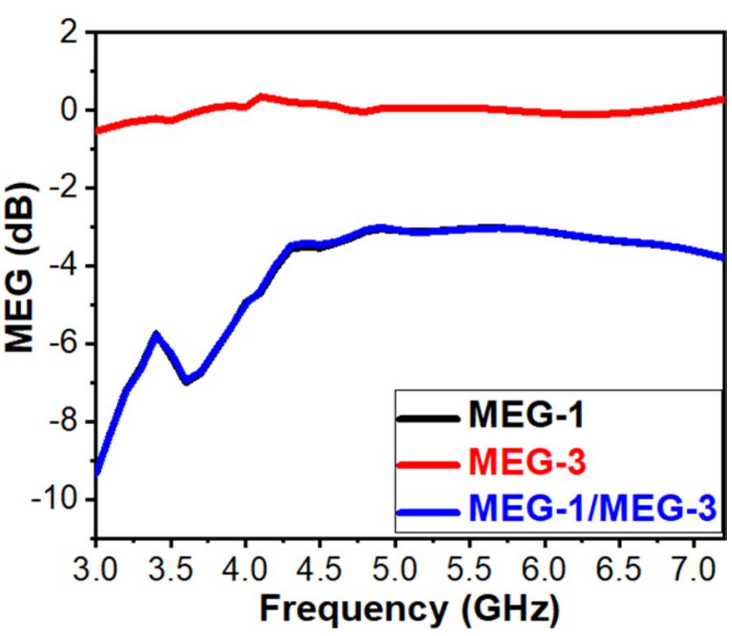

(b)

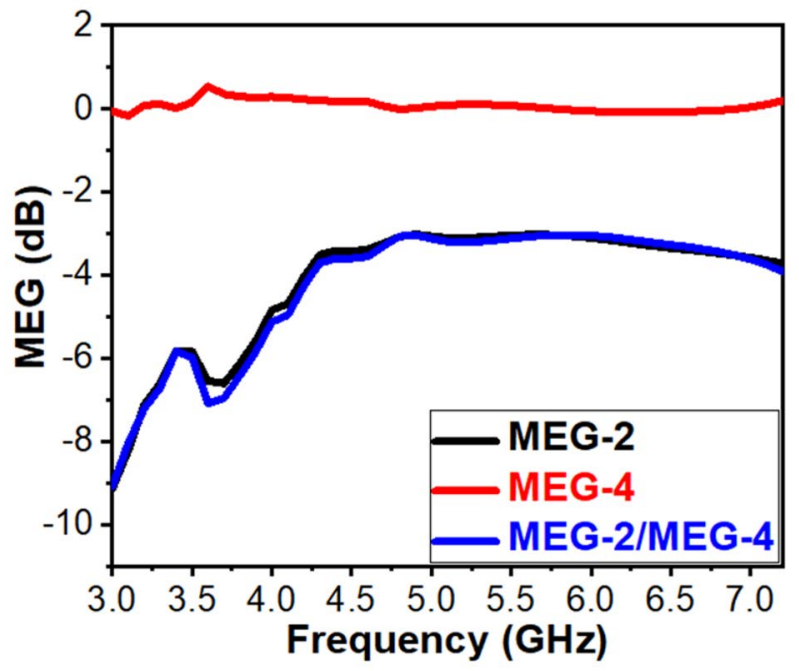

(c)

Fig. 25 MEG analysis between the ports $\mathbf{a} 1$ and 2, b 1 and 3, c 2 and 4 of four element antenna

ratios MEG-1/MEG-2, MEG-1/MEG-3, and MEG-2/MEG-4 must be less than $3 \mathrm{~dB}$. The same is observed in Fig. 25, the ratios are well below $3 \mathrm{~dB}$. The MEG is calculated using the following relations (5-6) [28]:

$$
\begin{aligned}
& \mathrm{MEG}_{i}=0.5\left[1-\left|S_{i i}\right|^{2}-\left|S_{i j}\right|^{2}\right] \\
& \mathrm{MEG}_{j}=0.5\left[1-\left|S_{i j}\right|^{2}-\left|S_{j j}\right|^{2}\right] .
\end{aligned}
$$

The CCL estimates the maximum limit up to which the message transmission can take place without any loss in the communication channel. The acceptable CCL value must be less than $0.4 \mathrm{bits} / \mathrm{s} / \mathrm{Hz}$. The CCL using the $\mid S$-parametersl is calculated from Eqs. (7-10) [28]:

$C_{\text {loss }}=-\log _{2}\left|\varphi^{R}\right|$

$\varphi^{R}=\left[\begin{array}{llll}\varphi_{11} & \varphi_{12} & \varphi_{13} & \varphi_{14} \\ \varphi_{21} & \varphi_{22} & \varphi_{23} & \varphi_{24} \\ \varphi_{31} & \varphi_{32} & \varphi_{33} & \varphi_{34} \\ \varphi_{41} & \varphi_{42} & \varphi_{43} & \varphi_{44}\end{array}\right]$

where

$\varphi_{i i}=1-\left|\sum_{n=1}^{N} S_{i n}^{*} S_{n i}\right|, \quad$ for $i, j=1,2,3$ and 4 


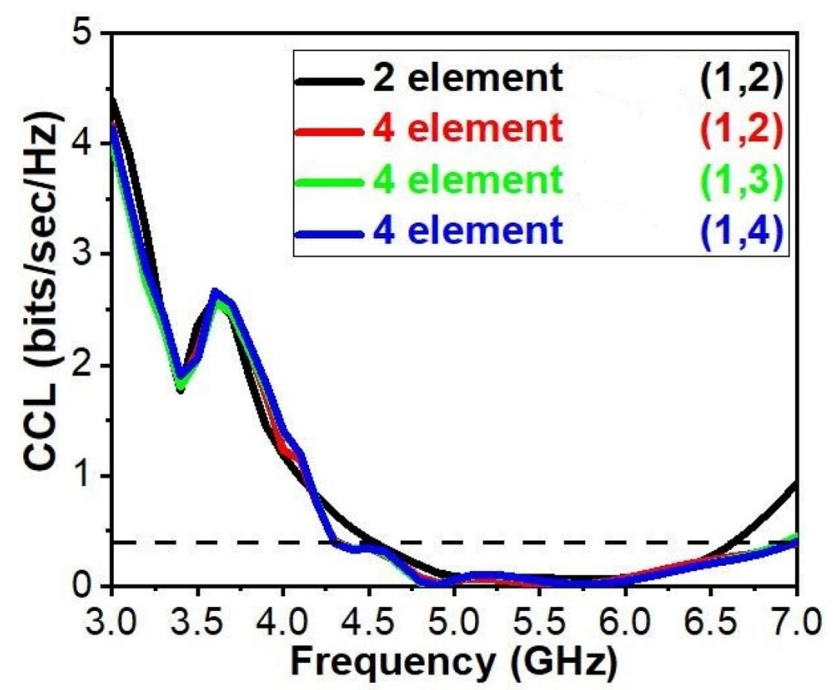

Fig. 26 Channel capacity loss between two antenna elements of two and four element design

$\varphi_{i j}=-\left|\sum_{n=1}^{N} S_{i n}^{*} S_{n j}\right|, \quad$ for $i, j=1,2,3$ and 4

The CCL estimated from IS-parameters| for the two element and four element antenna design is depicted in Fig. 26. It is observed that the CCL value is much below the desired maximum value $(<0.4 \mathrm{bits} / \mathrm{s} / \mathrm{Hz})$ over the entire operating frequency range.

The co-polarization and cross-polarization of the fabricated antenna are measured at $\varphi=0^{\circ}$ and $\varphi=90^{\circ}$. The measured bidirectional and Omni-directional pattern in E-plane, and H-plane are seen at $4.5 \mathrm{GHz}, 5.0 \mathrm{GHz}, 5.5 \mathrm{GHz}$ and $6.0 \mathrm{GHz}$ for two element antenna as shown in Fig. 27. Similarly, for the four port antenna the measured pattern is shown in Fig. 28.

The radiation pattern is more symmetrical at higher frequencies which may due to slotted patch which tends to suppress the back radiation and makes pattern symmetrical at a higher frequency.

The simulated gain and radiation efficiency of the proposed two element and four element antenna is depicted in Fig. 29. It is seen that the gain is about $3.5 \mathrm{dBi}$ at $5.5 \mathrm{GHz}$ and ranges between 3.25 and $4.25 \mathrm{dBi}$ in the operating bandwidth of two element antenna. Similarly, for four element antenna, a gain of about $4.95 \mathrm{dBi}$ is observed at $5.5 \mathrm{GHz}$ and ranges between 4.0 and $5.0 \mathrm{dBi}$ in the operating bandwidth. The radiation efficiency is well above $90 \%$ of both the antennas in the operating region.

A comparative analysis between the proposed four element and other wideband multiple antennas are studied in literature and is presented in Table 4. It is quite evident from the table that the designed antenna provides better performance over their counterparts. 
Fig. 27 Measured radiation pattern at $\varphi=0^{\circ}$ and $\varphi=90^{\circ}$ for two element antenna at a $4.5, \mathbf{b}$ 5.0 , c 5.5 and $\mathbf{d} 6.0 \mathrm{GHz}$
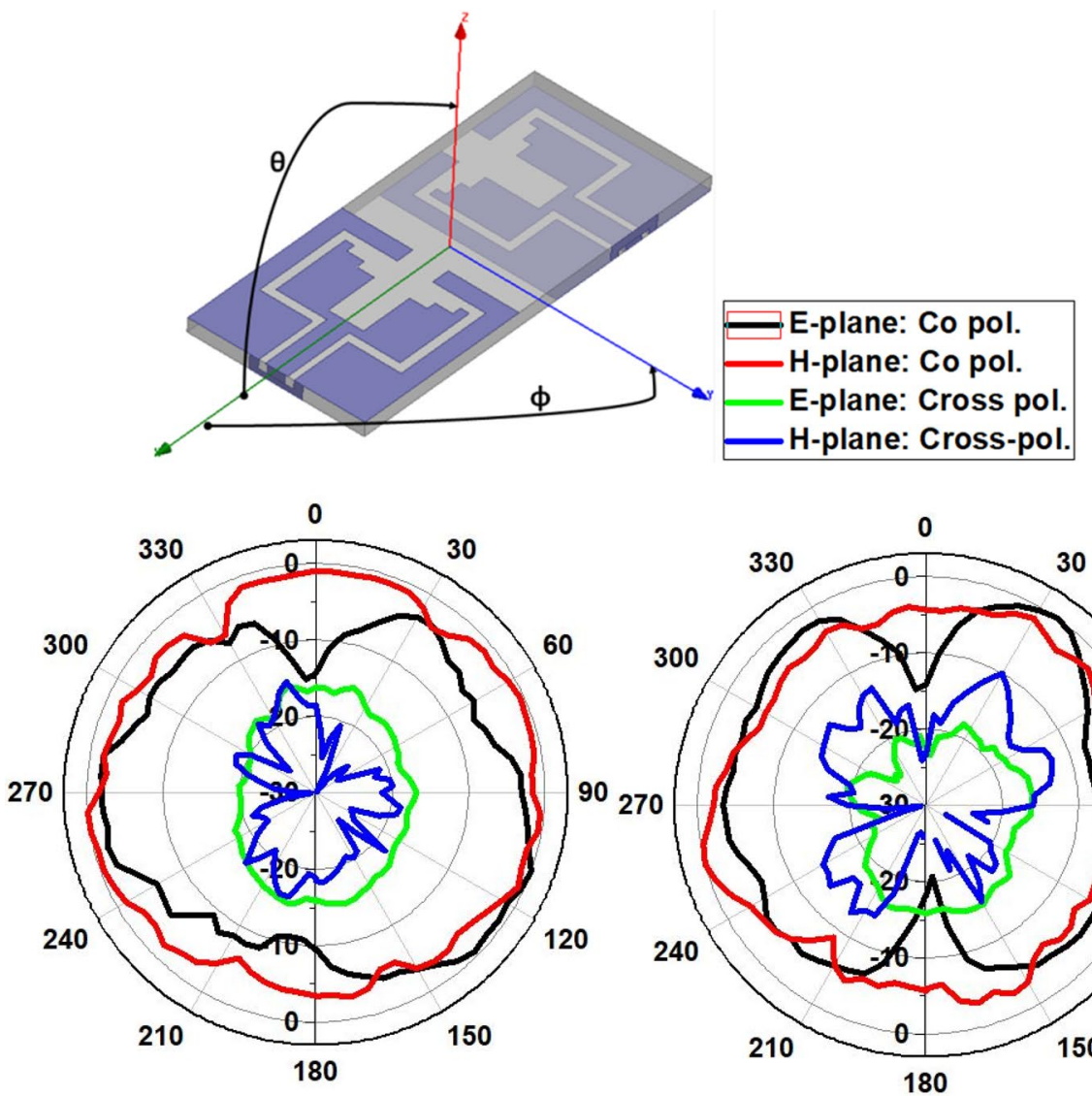

(a)

(b)

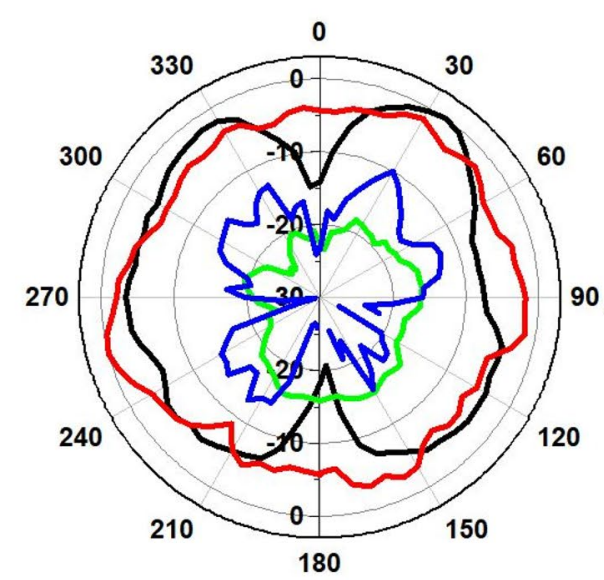

(c)

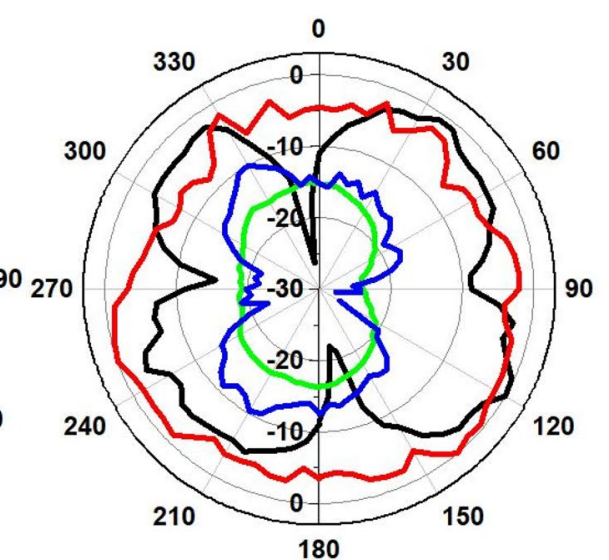

(d) 
Fig. 28 Measured radiation pattern at $\varphi=0^{\circ}$ and $\varphi=90^{\circ}$ for four element antenna at $\mathbf{a} 4.5, \mathbf{b}$ 5.0 , c 5.5 and $\mathbf{d} 6.0 \mathrm{GHz}$
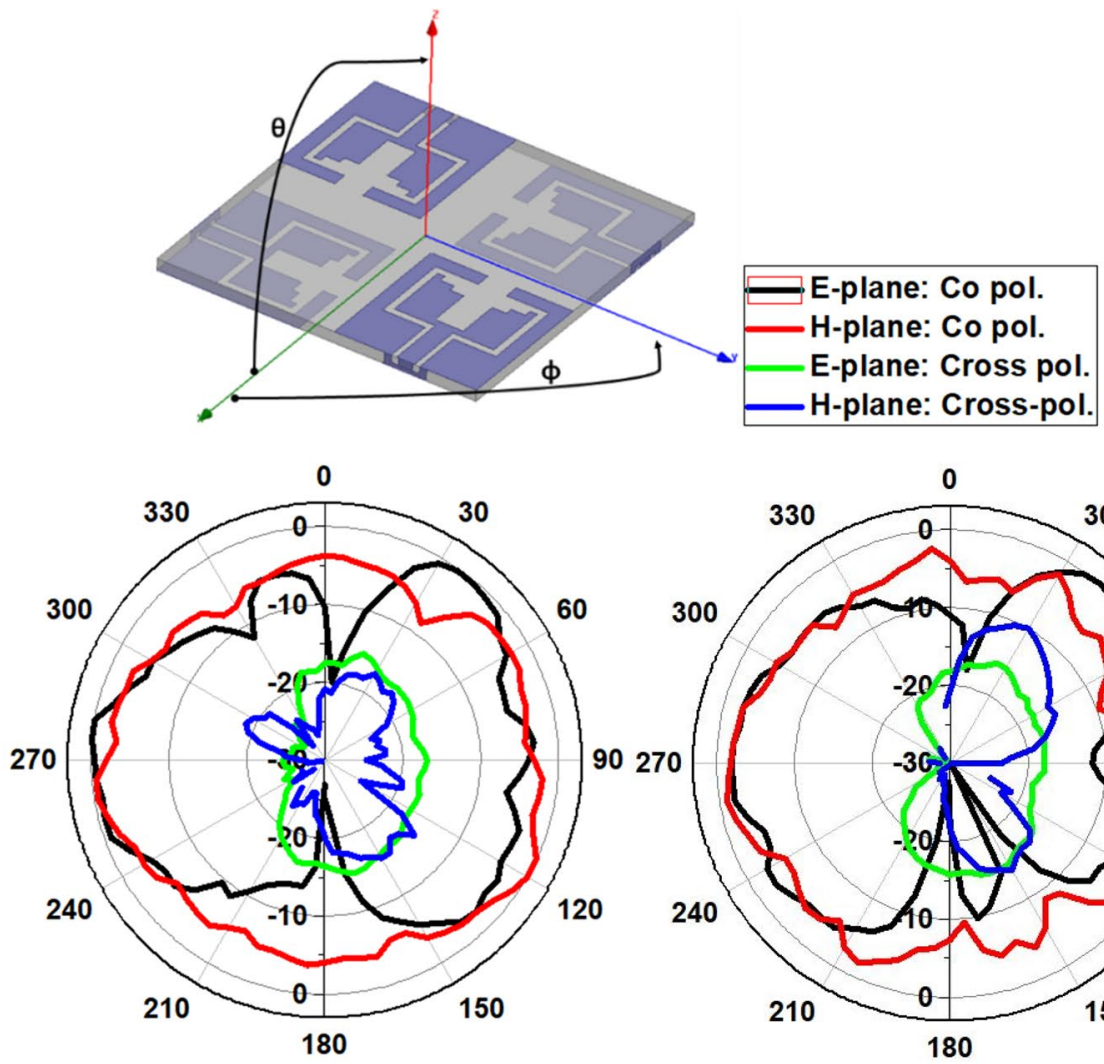

(a)

(b)

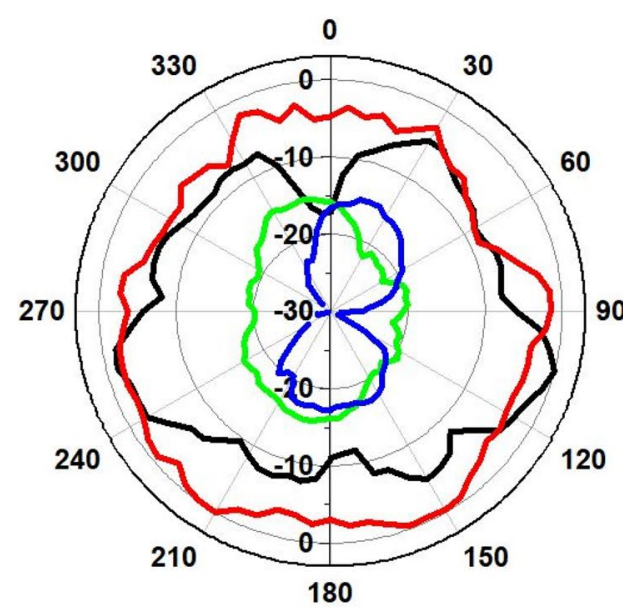

(c)

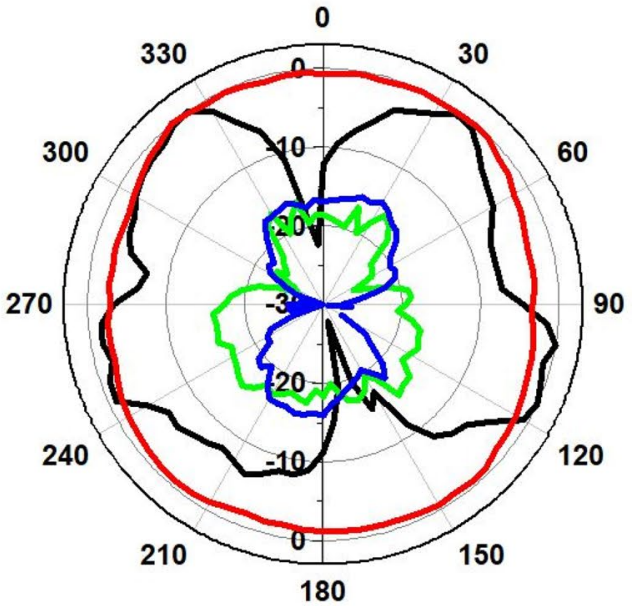

(d) 


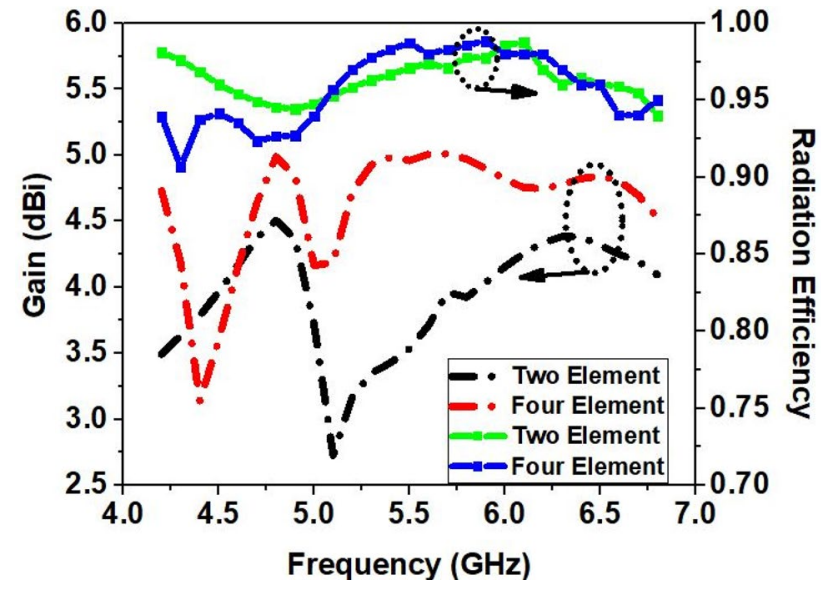

Fig. 29 Simulated gain and radiation efficiency of the proposed designs

\section{Conclusion}

A compact CPW fed two and four element antenna design with an operating bandwidth of $1500 \mathrm{MHz}(4.3-6.8 \mathrm{GHz})$ is proposed and its performance parameters are studied. The focus is on the improvement in isolation between the antenna elements. This high isolation is achieved in the proposed design without utilizing any decoupling methods, thus, totally benefits from the monopole asymmetrical structure. The essential diversity parameters like ECC, DG, TARC, MEG, and CCL are analyzed to have a minimum correlation between the antenna elements. The proposed antenna is intended to be used for WLAN, Wi-MAX, and satellite bands of the range corresponding to 4.70-6.19, 5.5-5.7, and 5-6 GHz.

Table 4 Comparing the performance parameters of the proposed design with existing designs

\begin{tabular}{lclllllll}
\hline Ref. nos. & Dim. $\left(\mathrm{mm}^{2}\right)$ & Range $(\mathrm{GHz})$ & Gain $(\mathrm{dBi})$ & Isolation $(\mathrm{dB})$ & ECC & DG $(\mathrm{dB})$ & CCL $(\mathrm{bits} / \mathrm{s} / \mathrm{Hz})$ & $\mathrm{MEG}(\mathrm{dB})$ \\
\hline$[16]$ & 4050 & $5.8-9.2$ & 1.24 & 21.0 & - & - & - & - \\
{$[17]$} & 2025 & $2.2-6.28$ & 2.75 & 10.0 & $<0.25$ & - & - & - \\
{$[18]$} & 2460 & $2.19-11.07$ & 6.5 & $>20.0$ & $<0.25$ & - & - & - \\
{$[19]$} & 6400 & 2.53 & 4.9 & $>15$ & $<0.01$ & - & - & - \\
{$[20]$} & 2400 & 2.45 & 3.4 & $>20$ & $<0.4$ & - & - & - \\
{$[21]$} & 2025 & $2-10.6$ & 3.0 & $>17$ & 0.003 & - & - & - \\
{$[22]$} & 4900 & 5.26 & 4.13 & $>20$ & $<0.03$ & 9.93 & - & - \\
{$[23]$} & 2445 & $5.18-5.22$ & 3.38 & $>20$ & - & - & $<.76$ \\
{$[29]$} & 3600 & $3.0-16.2$ & 6.0 & $>17.5$ & $<0.3$ & & - & - \\
{$[30]$} & 7225 & $3.0-10.6$ & 4.8 & $>15$ & $<0.2$ & - & - & - \\
{$[31]$} & 11,250 & $3.0-3.6$ & - & $>11$ & $<0.1$ & - & - & - \\
{$[32]$} & 8100 & $3.1-12$ & 3.2 & $>17$ & $<0.16$ & 9.6 & - \\
{$[33]$} & 2500 & $2-12$ & 3.15 & $>17$ & $<0.45$ & - & - \\
{$[34]$} & 4900 & $3.0-10.6$ & 6 & $>17$ & $<0.2$ & - & - \\
Prop. & 2025 & $4.3-6.8$ & 4.95 & $>20$ & $<0.2$ & $>9.8$ & 0.018 \\
\hline
\end{tabular}


Funding Open access funding provided by Manipal Academy of Higher Education, Manipal.

Open Access This article is licensed under a Creative Commons Attribution 4.0 International License, which permits use, sharing, adaptation, distribution and reproduction in any medium or format, as long as you give appropriate credit to the original author(s) and the source, provide a link to the Creative Commons licence, and indicate if changes were made. The images or other third party material in this article are included in the article's Creative Commons licence, unless indicated otherwise in a credit line to the material. If material is not included in the article's Creative Commons licence and your intended use is not permitted by statutory regulation or exceeds the permitted use, you will need to obtain permission directly from the copyright holder. To view a copy of this licence, visit http://creativecommons.org/licenses/by/4.0/.

\section{References}

1. S.S. Jehangir, R. Hussain, M.I. Hussein, M.S. Sharawi, Frequency reconfigurable Yagi-like MIMO antenna system with a wideband reflector. IET Microw. Antennas Propag. 14(7), 586-592 (2020)

2. A.S.M. Alqadami, M.F. Jamlos, P.J. Soh, S.K.A. Rahim, A. Narbudowicz, Left-handed compact MIMO antenna array based on wire spiral resonator for 5-GHz wireless applications. Appl. Phys. A 123(1), 64 (2017)

3. S. Khangarot, B.V. Sravan, N. Aluru, A.M. Saadh, R. Poonkuzhali, O.P. Kumar, T. Ali, M.M. Pai, A compact wideband antenna with detailed time domain analysis for wireless applications. Ain Shams Eng. J. (2020). https://doi.org/10.1016/j.asej.2020.02.008

4. S.S. Jehangir, M.S. Sharawi, A compact single layer fourport orthogonally polarized Yagi-like MIMO antenna system. IEEE Trans. Antennas Propag. (2020). https://doi.org/10.1109/ TAP.2020.2969810

5. M.N. Hasan, S. Chu, S. Bashir, A DGS monopole antenna loaded with U-shape stub for UWBMIMO applications. Microw. Opt. Technol. Lett. 61(9), 2141-2149 (2019)

6. N.O. Parchin, Y.I.A. Al-Yasir, A.H. Ali, I. Elfergani, J.M. Noras, J. Rodriguez, R.A. Abd-Alhameed, Eight-element dual-polarized MIMO slot antenna system for $5 \mathrm{G}$ smartphone applications. IEEE Access 7, 15612-15622 (2019)

7. A. Kumar Biswas, U. Chakraborty, Compact wearable MIMO antenna with improved port isolation for ultra-wideband applications. IETMicrow. Antennas Propag. 13(4), 498-504 (2019)

8. H. Yalduz, B. Koç, L. Kuzu, M. Turkmen, An ultra-wide band low-SAR flexible metasurface-enabled antenna for WBAN applications. Appl. Phys. A 125(9), 609 (2019)

9. M. Ikram, M.S. Sharawi, A. Shamim, Compact circular connected monopole antenna arrays for wideband MIMO applications. IETMicrow. Antennas Propag. 12(13), 2122-2127 (2018)

10. R. Hussain, M.U. Khan, M.S. Sharawi, Design and analysis of a miniaturized meandered slot-line-based quad-band frequency agile MIMO antenna. IEEE Trans. Antennas Propag. 68(3), 24102415 (2019)

11. S. Nandi, A. Mohan, CRLH unit cell loaded triband compact MIMO antenna for WLAN/WiMAX applications. IEEE Antennas Wirel. Propag. Lett. 16, 1816-1819 (2017)

12. Saadh, A. M., Ashwath, K., Ramaswamy, P., Ali, T., \& J. Anguera, A uniquely shaped MIMO antenna on FR4 material to enhance isolation and bandwidth for wireless applications. AEU Int. J. Electron. Commun. 123, 153316 (2020)

13. K. Takahashi, R. Bakar, H. Arai, T. Ihara, Y. Ishikawa, Design of four elements MIMO antenna using the theory of characteristic mode. In: International Symposium on Antennas and Propagation (ISAP). Okinawa 2016, 232-233 (2016)

14. H. Li, J. Xiong, S. He, A compact planar MIMO antenna system of four elements with similar radiation characteristics and isolation structure. IEEE Antennas Wirel. Propag. Lett. 8, 1107-1110 (2009)

15. D. Sarkar, K.V. Srivastava, A compact four-element MIMO/diversity antenna with enhanced bandwidth. IEEE Antennas Wirel. Propag. Lett. 16, 2469-2472 (2017)

16. P.S. Kumar, B.C. Mohan, Design of a compact two element MIMO antenna with improved bandwidth and isolation. In: 2015 International Conference on Microwave, Optical and Communication Engineering (ICMOCE), (Bhubaneswar, 2015), pp. 389-392

17. R. Anitha, P.V. Vinesh, K.C. Prakash, P. Mohanan, K. Vasudevan, A compact quad element slotted ground wideband antenna for MIMO applications. IEEE Trans. Antennas Propag. 64(10), 4550-4553 (2016)

18. X.L. Liu, Z.D. Wang, Y.Z. Yin, J. Ren, J.J. Wu, A compact ultrawidebandMIMO antenna using QSCA for high isolation. IEEE Antennas Wirel. Propag. Lett. 13, 1497-1500 (2014)

19. D. Sarkar, S. Kushmanda, V.S. Kumar, A compact dual band four element MIMO antenna for pattern diversity applications. In: 2016 IEEE 5th Asia-Pacific Conference on Antennas and Propagation (APCAP). IEEE (2016)

20. A. Ramachandran, S.V. Pushpakaran, M. Pezholil, V. Kesavath, A four-port MIMO antenna using concentric square-ring patches loaded with CSRR for high isolation. IEEE Antennas Wirel. Propag. Lett. 15, 1196-1199 (2015)

21. S. Tripathi, A. Mohan, S. Yadav, A compact Koch fractal UWB MIMO antenna with WLAN band-rejection. IEEE Antennas Wirel. Propag. Lett. 14, 1565-1568 (2015)

22. L. Malviya, K.P. Rajib, V.K. Machavaram, A $2 \times 2$ dual-band MIMO antenna with polarization diversity for wireless applications. Prog. Electromagn. Res. 61, 91-103 (2016)

23. K. Paramayudha et al., Four port diversity patch antennas for MIMO WLAN application. In: 2016 International Seminar on Intelligent Technology and its Applications (ISITIA). IEEE (2016)

24. Mohammad Saadh, A. W., Khangarot, S., Sravan, B. V., Aluru, N., Ramaswamy, P., Ali, T., \& Pai, M. M. A compact four-element MIMO antenna for WLAN/WiMAX/satellite applications. Int .J. Commun. Syst. 33(14), e4506 (2020)

25. M.S. Sharawi, Current misuses and future prospects for printed multiple-input, multiple-output antenna systems [wireless corner]. IEEE Antennas Propag. Mag. 59(2), 162-170 (2017)

26. S.H. Chae, O. Se-keun, P. Seong-Ook, Analysis of mutual coupling, correlations, and TARC in WiBroMIMO array antenna. IEEE Antennas Wirel. Propag. Lett. 6, 122-125 (2007)

27. M. Manteghi, Y. Rahmat-Samii, Multiport characteristics of a wide-band cavity backed annular patch antenna for multipolarization operations. IEEE Trans. Antennas Propag. 53(1), 466-474 (2005)

28. T. Kumari, G. Das, A. Sharma, R.K. Gangwar, Design approach for dual element hybrid MIMO antenna arrangement for wideband applications. Int. J. RF Microw. Comput. Aided Eng. 29(1), e21486 (2019)

29. W. Wu, B. Yuan, A. Wu, A quad-element UWB-MIMO antenna with band-notch and reduced mutual coupling based on EBG structures. Int. J. Antennas Propag. 2018, 8490740. https://doi. org/10.1155/2018/8490740

30. R. Mathur, S. Dwari, 8-Port multibeam planar UWB-MIMO antenna with pattern and polarisation diversity. IETMicrow. Antennas Propag. 13(13), 2297-2302 (2019)

31. X. Zhang, Y. Li, W. Wang, W. Shen, Ultra-wideband 8-port MIMO antenna array for $5 \mathrm{G}$ metal-frame smartphones. IEEE Access 7, 72273-72282 (2019) 
32. M.G.N. Alsath, H. Arun, Y.P. Selvam, M. Kanagasabai, S. Kingsly, S. Subbaraj, R. Natarajan, An integrated tri-band/UWB polarization diversity antenna for vehicular networks. IEEE Trans. Veh. Technol. 67(7), 5613-5620 (2018)

33. M.S. Khan, A. Iftikhar, R.M. Shubair, A.D. Capobianco, B.D. Braaten, D.E. Anagnostou, Eight-element compact UWB-MIMO/ diversity antenna with WLAN band rejection for 3G/4G/5G communications. IEEE Open J. Antennas Propag. 1, 196-206 (2020)
34. A.A.R. Saad, Approach for improving inter-element isolation of orthogonally polarised MIMO slot antenna over ultra-wide bandwidth. Electron. Lett. 54(18), 1062-1064 (2018)

Publisher's Note Springer Nature remains neutral with regard to jurisdictional claims in published maps and institutional affiliations. 